\title{
Development of Magnetically Soft Amorphous Microwires for Technological Applications
}

\author{
Valentina Zhukova ${ }^{1,2}\left({ }^{\circ}\right.$, Paula Corte-Leon ${ }^{1,2}\left(\mathbb{D}\right.$, Juan Maria Blanco ${ }^{2}$, Mihail Ipatov ${ }^{1,2}($, \\ Lorena Gonzalez-Legarreta ${ }^{3}$, Alvaro Gonzalez ${ }^{1}$ and Arcady Zhukov ${ }^{1,2,4, * \mathbb{C}}$
}

1 Deptartment of Advanced Polymers and Materials: Physics, Chemistry and Technology, Faculty of Chemistry, University of Basque Country, UPV/EHU, 20018 San Sebastian, Spain; valentina.zhukova@ehu.es (V.Z.); paula.corte@ehu.eus (P.C.-L.); mihail.ipatov@ehu.eus (M.I.); alvaro.gonzalezv@ehu.eus (A.G.)

2 Deptartement of Applied Physics, EIG, University of Basque Country, UPV/EHU, 20018 San Sebastian, Spain; juanmaria.blanco@ehu.eus

3 Deptartment QUIPRE, Inorganic Chemistry-University of Cantabria, Nanomedice-IDIVAL, Avda. de Los Castros 46, 39005 Santander, Spain; lorena.glegarreta@gmail.com

4 IKERBASQUE, Basque Foundation for Science, 48011 Bilbao, Spain

* Correspondence: arkadi.joukov@ehu.es; Tel.: +34-94-3018-611; Fax: +34-94-3017-130

\section{check for}

updates

Citation: Zhukova, V.; Corte-Leon, P.;

Blanco, J.M.; Ipatov, M.;

Gonzalez-Legarreta, L.; Gonzalez, A.;

Zhukov, A. Development of

Magnetically Soft Amorphous

Microwires for Technological

Applications. Chemosensors 2022, 10,

26. https://doi.org/10.3390/

chemosensors10010026

Academic Editor: Nicole

Jaffrezic-Renault

Received: 23 November 2021

Accepted: 1 January 2022

Published: 7 January 2022

Publisher's Note: MDPI stays neutral with regard to jurisdictional claims in published maps and institutional affiliations.

Copyright: () 2022 by the authors Licensee MDPI, Basel, Switzerland. This article is an open access article distributed under the terms and conditions of the Creative Commons Attribution (CC BY) license (https:// creativecommons.org/licenses/by/ $4.0 /)$.

\begin{abstract}
Amorphous magnetic microwires can be suitable for a variety of technological applications due to their excellent magnetic softness and giant magnetoimpedance (GMI) effect. Several approaches for optimization of soft magnetic properties and GMI effect of magnetic microwires covered with an insulating, flexible, and biocompatible glass coating with tunable magnetic properties are overviewed. The high GMI effect and soft magnetic properties, achieved even in as-prepared Co-rich microwires with a vanishing magnetostriction coefficient, can be further improved by appropriate heat treatment (including stress-annealing and Joule heating). Although as-prepared Fe-rich amorphous microwires exhibit low GMI ratio and rectangular hysteresis loops, stress-annealing, Joule heating, and combined stress-annealed followed by conventional furnace annealing can substantially improve the GMI effect (by more than an order of magnitude).
\end{abstract}

Keywords: magnetic microwires; sensor applications; post-processing; magnetic anisotropy; magnetostriction

\section{Introduction}

Magnetic functional cost-effective materials with tunable magnetic properties and reduced dimensions are highly demanded by numerous technological applications, such as sensors, security electronic surveillance, microelectronics, medicine, automobile and aircraft industries, energy harvesting and conversion, home entertainment, electrical engineering, magnetic recording, magnetic memories, etc. [1-6].

Among the most demanded properties of magnetic functional materials can be listed: good magnetic softness, energyharvesting, magnetocaloric effect, magnetoresistance effects (AMR, GMR, TMR), giant magnetoimpedance effect, GMI, magnetocaloric effect, MCE, Hall effect, etc. [1-9]. Cost and performance of devices and sensors are linked to the magnetic material properties and cost/price.

Amorphous magnetic materials produced by rapid quenching from the melt are considered among the most appropriate materials due to excellent soft magnetic properties combined with high mechanical and anticorrosive properties, and relatively simple and cost-effective fabrication technology [3,4,10-15]. The origin of such unique combination of properties of amorphous materials is linked to their glassy-like structure characterized by the absence of defects typical for crystalline structure [10-15].

Generally, amorphous materials can be prepared in the form of ribbons or wires [3,4,10-15]. For the implementation of certain magnetic properties (such as high GMI effect or magnetic bistability), cylindrical geometry is more suitable $[16,17]$. Therefore, different families 
of amorphous wires became subjects of extensive studies, and numerous applications of amorphous wires have been proposed [16-27].

The excellent magnetic softness exhibited by amorphous materials is intrinsically related to the GMI effect originated by the dependence of the skin depth, $\delta$, of a magnetic conductor on an applied magnetic field, $H$, given as [28-31]:

$$
\delta=\frac{1}{\sqrt{\pi \sigma \mu_{\varphi} f}}
$$

where $\mu_{\varphi}$ is the circumferential magnetic permeability, $\sigma$ is the electrical conductivity, and $f$ is the $\mathrm{AC}$ current frequency.

High sensitivity of magnetic wire impedance, $Z$, to an applied magnetic field, $H$, or even to applied stresses is crucial for development of numerous high-performance magnetic and magnetoelastic sensors [30-39]. For characterization of the GMI effect, the commonly used parameter is the GMI ratio, $\Delta Z / Z$, defined as [28-33]:

$$
\left.\Delta Z / Z=\left[Z(H)-Z\left(H_{\max }\right)\right] / Z\left(H_{\max }\right)\right] \times 100,
$$

where $H_{\max }$ is the maximum applied $D C$ magnetic field (as a rule, below a few $\mathrm{kA} / \mathrm{m}$ ).

The other value of merit is the field sensitivity, $\eta$, given as [40]:

$$
\eta=\frac{\partial\left(\frac{\Delta Z}{Z}\right)}{\partial H}
$$

Up until now, the highest $\Delta Z / Z$ s are reported in amorphous microwires. Therefore, almost all reported GMI applications involve the use of magnetically soft amorphous wires with vanishing magnetostriction coefficient, $\lambda_{s}[16,18,33-36]$.

Another peculiar feature of amorphous magnetic wires is spontaneous magnetic bistability associated with magnetization reversal through single and large Barkhausen jump and hence perfectly rectangular hysteresis loops [41-43]. This behavior is typically observed in amorphous wires of magnetostrictive compositions (in glass-coated microwires for $\lambda_{s}>0$ ) and explained by the domain structure of amorphous wires consisting of an inner single domain with axial orientation surrounded by an outer domain shell with transverse orientation (radial for $\lambda_{s}>0$ or circumferential for $\lambda_{s}<0$ ) [41-45]. The ultrafast propagation of a single domain wall (DW) within a single inner domain, which starts from the end closure domains, is responsible for spontaneous magnetic bistability [41-45].

Amorphous wires can be prepared by various methods, all of them involving rapid melt quenching $[12,13,46-50]$. The so-called Taylor-Ulitovsky technique allows preparation of magnetic microwires in a wider range of diameters, $d,(0.2 \leq d \leq 100 \mu \mathrm{m})$ coated by flexible and insulating glass coating [49-51]. Glass coating provides additional functionalities, such as improved mechanical and anticorrosive properties and biocompatibility $[13,14,22,24,25]$.

This combination of magnetic and physical properties (good magnetic softness, magnetic bistability, GMI effect, good mechanical and anticorrosive properties, and biocompatibility) makes glass-coated microwires highly attractive for various applications and provides unique possibilities for basic research (studies of single DW propagation, GMI effect at $\mathrm{GHz}$ frequencies, among others).

In this review, we present trends related to optimization of soft magnetic properties and GMI effect of amorphous glass magnetic microwires suitable for various technological applications. This review is organized as follows: the fabrication method and experimental methods are described in Section 2. In Section 3, we review magnetic properties of asprepared amorphous magnetic microwires. Finally, trends of magnetic softness and GMI effect are provided in Section 4. 


\section{Materials and Methods}

Preparation of metallic ( $\mathrm{Pb}, \mathrm{Sb}, \mathrm{Bi}, \mathrm{Au}, \mathrm{Ag}, \mathrm{Cu}, \mathrm{Fe}, \mathrm{Sn}, \mathrm{Cd}, \mathrm{Co}, \mathrm{Ga})$ microwires by drawing out of the molten metal from a heated by flame glass tube was first reported in 1924 [52]. Almost continuous process of metallic nonmagnetic wire preparation was developed in 1964 [53]. Amorphous magnetic microwire preparation using the technology developed initially for nonmagnetic alloys was reported in the 1970s and 1980s [13,54]. Finally, this technology has been substantially modified: the modern fabrication facility is provided by a feedback system allowing control of main manufacturing parameters and geometry of the microwire (metallic nucleus diameter, $d$, and total diameter of the microwire, $D)$ using a PC $[55,56]$. In recent publications, this preparation method is usually referred to as the modified Taylor-Ulitovsky method and/or the quenching and drawing method [54,56].

This preparation method involves the simultaneous rapid solidification of a composite microwire (a metallic nucleus inside a glass capillary) as it passes through a stream of coolant (water or oil) (see Figure 1a). Previously, a metallic alloy ingot (typically a few grams) of the desired chemical composition is melted inside a glass (Pyrex or Duran-like) tube by a high frequency (typically $350-500 \mathrm{kHz}$ ) inductor. Then a glass capillary is formed from the softened glass, which is captured by a rotating pick-up spool. The molten metallic alloy fills the glass capillary and a microwire with a metallic nucleus completely covered by a continuous, thin and flexible glass coating is formed (see Figure 1a,b). The metallic nucleus diameter, $d$, and glass-coating thickness can be tuned by the speed at which the wire is drawn and by the glass tube feed rate.

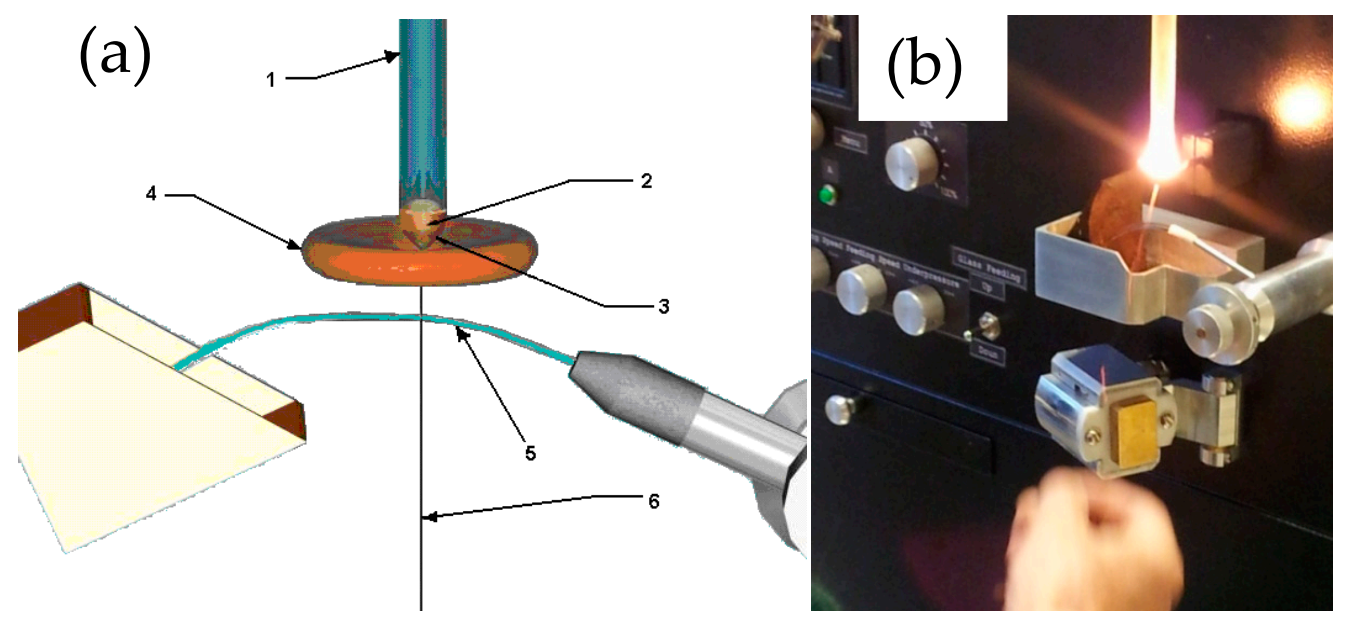

Figure 1. Schematic picture of the fabrication Taylor-Ulitovsky process allowing preparation of glass-coated microwires (a) (1-glass-tube, 2-alloy ingot, 3-glass-cone, 4-AC inductor, 5-coolant (water or oil) jet, 6-glass-coated microwire) and an image of the experimental setup for fabrication of microwires (b).

The high-frequency magnetic field of the inductor, high temperature itself, and interaction of the metallic alloy and glass can affect the chemical homogeneity of the glass-coated microwire; small glass particles can be entrained in the melt under the action of highfrequency magnetic field of the inductor [56,57]. These glass particles can be captured by the metallic nucleus and by the glass capillary during casting and even interrupt the process [56,57].

Although insulating glass coating protects from the surface oxidation typically observed in conventional (uncoated) amorphous wires, the presence of an interfacial layer between the metallic nucleus and glass coating is reported for various chemical compositions of metallic alloys (including Co- and Fe-based magnetic alloys) [57-59]. One of the examples is provided in Figure 2, where the element mappings obtained by scanning electron microscope JEOL JSM- 6610 for the $\mathrm{Fe}_{72,2} \mathrm{~B}_{13,2} \mathrm{Si}_{10,9} \mathrm{C}_{2}$ microwires are provided. A 
modification in $\mathrm{Fe}, \mathrm{Si}$, and $\mathrm{C}$ contents along the microwire radius is observed between the metal core and the glass coating. The interfacial layer thickness evaluated for various Fe-rich microwires is about $0.5 \mu \mathrm{m}$ [58,59], which is quite similar to those provided for microwires from nonmagnetic alloys obtained by various methods [57].

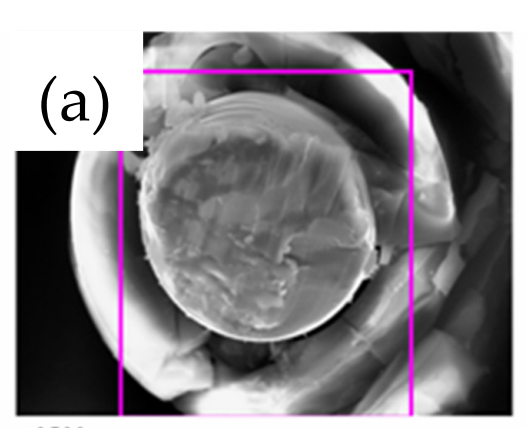

$\times 3500$

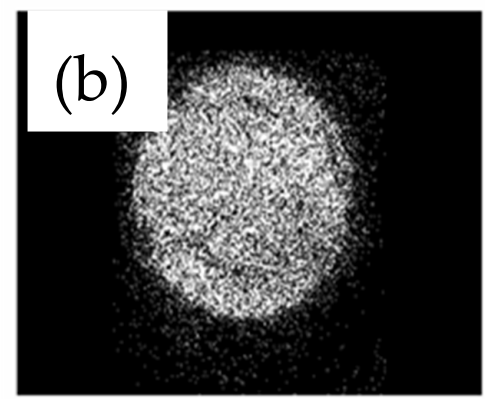

Fe Ka1

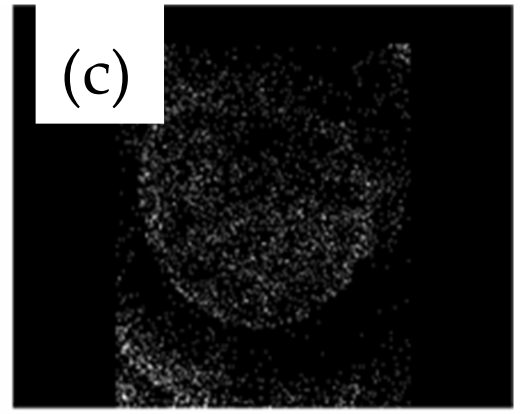

CKa1_2
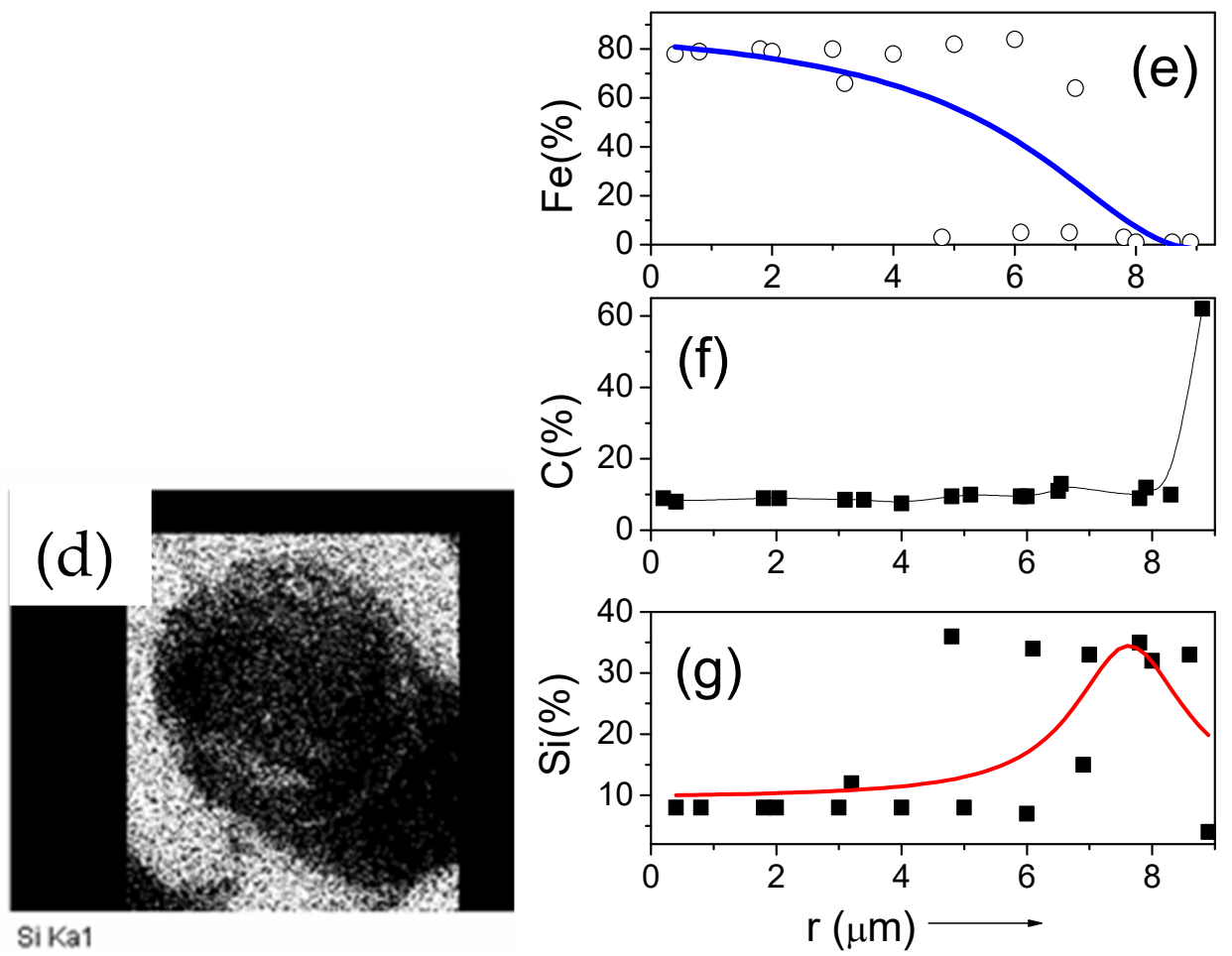

Figure 2. Cross section image (a) mapping of the $\mathrm{Fe}_{72.2} \mathrm{~B}_{13.2} \mathrm{Si}_{10.9} \mathrm{C}_{2}$ microwire $(d=8 \mu \mathrm{m}, D=11.94 \mu \mathrm{m})$ for $\mathrm{Fe}(\mathbf{b}), \mathrm{C}(\mathbf{c})$, and $\mathrm{Si}(\mathbf{d})$, and distribution of $\mathrm{Fe}(\mathbf{e}), \mathrm{C}(\mathbf{f})$ and $\mathrm{Si}(\mathrm{g})$ elements along the microwire radius, $r$, for $\mathrm{Fe}_{72,2} \mathrm{~B}_{13,2} \mathrm{Si}_{10,9} \mathrm{C}_{2}$ microwire $(d=13.2 \mu \mathrm{m}, D=17.6 \mu \mathrm{m})$. Reproduced with permission from [58].

The interfacial layer origin has been attributed to various phenomena [57-59]: solid state solutions between glass coating and metal core, uncompensated molecular forces at the interface between the glass and the metal nucleus, or the formation of stable chemical compounds with a structure that is different (from a crystallographic viewpoint) from the interacting materials. For nonmagnetic metallic nucleus, existence of correlation between the content of nonmetallic inclusions in the interfacial layer and the $\rho$-ratio between metallic nucleus diameter, $d$, and total diameter, $D(\rho=d / D)$ is observed: the content of nonmetallic inclusions decreased increasing $\rho$-ratio [57]. Accordingly, for a thin metallic nucleus the existence of an interfacial layer may be more relevant.

The presence of bubbles spontaneously distributed in the glass coating is reported in Fe- and Co-rich microwires $[60,61]$. One of the examples is shown in Figure 3 . The 
presence of such bubbles can produce internal stress heterogeneity within the metallic nucleus [58-61]. The equilibrium melt droplet shape is affected by the shape of the HF inductor, the electromagnetic field inside the molten ingot, ingot mass, alloy viscosity, and glass properties (melting temperature and thermal expansion coefficient), among other parameters.

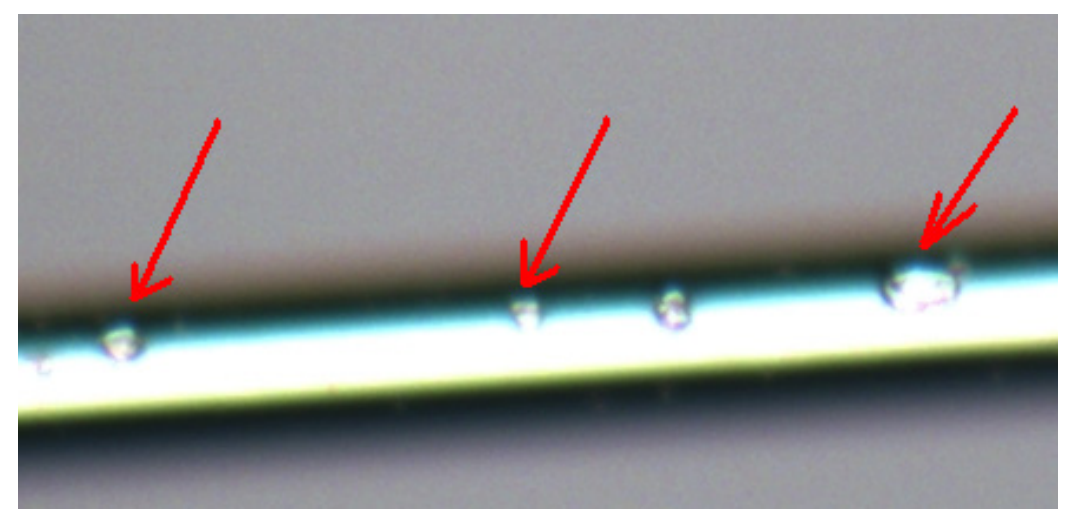

Figure 3. Bubbles in the glass shell observed in $\mathrm{Fe}_{74} \mathrm{~B}_{13} \mathrm{Si}_{11} \mathrm{C}_{2}$ microwire $(\rho \approx 0.8)$ (indicated by the arrows). Reproduced with permission from [61].

The simultaneous rapid solidification of a metallic nucleus surrounded by a glass coating with different thermal expansion coefficients is the source of additional internal stresses [62-66]. Accordingly, in addition to quenching internal stresses, $\sigma_{i q}$, arising from the rapid melt quenching itself [62], there are two more sources of internal stresses: stresses originating from the different thermal expansion coefficients of metallic alloy and glass, $\sigma_{i t}$, and stresses produced by wire drawing, $\sigma_{i d}$, [63-66]. Most of experimental and theoretical results point out that $\sigma_{i t} » \sigma_{i q}$ and $\sigma_{i t} \gg \sigma_{i d}$. Additionally, $\sigma_{i t}$ value is of tensor character and can be tuned by the microwire geometry through the $\rho$-ratio $(\rho=d / D)$.

In the most simplified approximation, $\sigma_{i}$ has been expressed as $[49,65,67]$ :

$$
\sigma_{\varphi}=\sigma_{r}=\varepsilon \mathrm{Ek} \Delta /(\mathrm{k} / 3+1) \Delta+4 / 3 ; \sigma_{z}=\sigma_{r}(\mathrm{k}+1) \Delta+2 /(\mathrm{k} \Delta+1)
$$

where $\sigma_{\varphi}, \sigma_{r}$, and $\sigma_{z}$ are circular, radial, and axial stresses, $\Delta=\left(1-\rho^{2}\right) / \rho^{2}, \mathrm{k}=E_{g} / E_{m}, E_{m}$, $E_{g}$-Young modulus of metallic nucleus and glass, respectively, $\varepsilon=\left(\alpha_{m}-\alpha_{g}\right)\left(T_{m}-T_{\text {room }}\right)$, $\alpha_{m}, \alpha_{g}$ are thermal expansion coefficients of metallic nucleus and glass, respectively, and $T_{m}, T_{\text {room }}$ are melting and room temperatures.

The more detailed theoretical estimations give $\sigma_{i t}$ up to $4 \mathrm{GPa}[63,64,66]$, since $\sigma_{z}$ is the largest in most part of the metallic nucleus volume (roughly up to $r \sim 0.85 R$, where $R$ is the metallic nucleus radius) $[63,64,66] ; \sigma_{i q}$ and $\sigma_{i d}$ are roughly an order of magnitude lower than $\sigma_{i t}[63,64,66]$.

In spite of aforementioned peculiarities of the Taylor-Ulitovsky preparation process (some of them are common with other methods involving rapid melt quenching), this technique is suitable for preparation of up to $10 \mathrm{~km}$-long continuous glass-coated magnetic microwires with metallic nucleus diameters from 0.2 up to $100 \mu \mathrm{m}$. For most typical $d$ values (about 10-30 $\mu \mathrm{m}$ ), about $1 \mathrm{~km}$ of glass-coated microwires can be prepared from $1 \mathrm{~g}$ of metallic alloy ingot.

In this review, we give attention to the development of amorphous microwires with magnetically soft properties exhibiting GMI effect.

Geometries of the microwires ( $d$ and $D$-values) provided are the average values determined by optical microscopy at several places along the microwires. Typically, the spread in $d$ and $D$-values is below $0.5 \mu \mathrm{m}$.

Hysteresis loops of as-prepared and heat-treated microwires were evaluated using the fluxmetric method, described in detail elsewhere [68]. Hysteresis loops have been represented as the dependence of normalized magnetization, $M / M_{0},(M-$ the magnetic 
moment at a given magnetic field and $M_{0}$ - magnetic moment at the maximum magnetic field amplitude $H_{m}$ ) on magnetic field, $H$. Such hysteresis loops are useful for comparison of samples with different chemical compositions (and, hence, different saturation magnetization). The magnetic field is created by a long (about $12 \mathrm{~cm}$ ) and thin (about $8 \mathrm{~mm}$ in diameter) solenoid. Hysteresis loops are measured using a $20 \mathrm{~mm}$-long pick-up coil.

A vector network analyzer and a microstrip sample holder were employed to evaluate the microwire impedance, $Z$, from the reflection coefficient, $S_{11}$, as previously described $[69,70]$. This technique allows $Z$ measurements at frequencies, $f$, up to $\mathrm{GHz}$ frequencies $[69,70]$. Magnetic field, $H$, dependence of $Z$ has been evaluated by placing the microstrip sample holder with microwire inside a sufficiently long solenoid producing $H$ up to $20 \mathrm{kA} / \mathrm{m}$. The GMI ratio, $\Delta Z / Z$, has been evaluated from $Z(H)$ dependence by using Equation (2).

The X-ray diffraction (XRD) method was used to prove the amorphous structure of microwires studied: all present XRD patterns with a broad halo. X-ray studies were performed using a Bruker (D8 Advance) X-ray diffractometer with $\mathrm{Cu} \mathrm{K}_{\alpha}(\lambda=1.54 \AA)$ radiation. For annealing, we used a standard Thermolyne furnace. All samples were annealed at temperatures, $T_{a n n}$, below the crystallization temperature. Typically, the crystallization of amorphous microwires was observed at $T_{a n n} \geq 500{ }^{\circ} \mathrm{C}[68,71]$. In the case of stress-annealing, the stress value in the metallic nucleus, $\sigma_{m}$, was evaluated considering different Young's modulus of metal, $E_{2}$, and glass, $E_{1}$, as described elsewhere [68,71]:

$$
\sigma_{m}=\frac{K \cdot P}{K \cdot S_{m}+S_{g l}}
$$

where $K=E_{2} / E_{1}, S_{m}$ and $S_{g l}$ are the metallic nucleus and glass coating cross sections, respectively, and $P$ is the applied mechanical load. As a rule, $\sigma_{m}$ values were below $900 \mathrm{MPa}$. The tensile stress was applied during annealing and during cooling of the sample in the furnace. Typically, annealing duration, $t_{a n n}$, was $60 \mathrm{~min}$.

Values of the magnetostriction coefficients, $\lambda_{s}$, were measured by the small angle magnetization rotation (SAMR) technique using the setup adapted for microwires [72]. Table 1.

The compositions, diameters, and $\lambda_{s}$ values of the microwires studied are provided in

Table 1. Composition and geometry of the glass-coated microwires studied.

\begin{tabular}{|c|c|c|c|c|}
\hline Composition & $\begin{array}{l}\text { Metallic Nucleus } \\
\text { Diameter, d }(\mu \mathrm{m})\end{array}$ & $\begin{array}{l}\text { Total Diameter, } \\
\text { D ( } \mu \mathrm{m})\end{array}$ & $\begin{array}{c}\text { Ratio } \\
\rho=\mathrm{d} / \mathrm{D}\end{array}$ & $\begin{array}{l}\text { Magnetostriction Coefficient, } \\
\qquad \lambda_{s} \times 10^{6}\end{array}$ \\
\hline $\mathrm{Fe}_{74} \mathrm{~B}_{13} \mathrm{Si}_{11} \mathrm{C}_{2}$ & 16.6 & 20.8 & 0.8 & 38 \\
\hline $\mathrm{Fe}_{74} \mathrm{Si}_{11} \mathrm{~B}_{13} \mathrm{C}_{2}$ & 14.6 & 21.8 & 0.55 & 38 \\
\hline $\mathrm{Fe}_{75} \mathrm{~B}_{9} \mathrm{Si}_{12} \mathrm{C}_{4}$ & 15.2 & 17.2 & 0.88 & 38 \\
\hline $\mathrm{Fe}_{65} \mathrm{Si}_{15} \mathrm{~B}_{15} \mathrm{C}_{5}$ & 15 & 23.8 & 0.63 & 38 \\
\hline $\mathrm{Fe}_{65} \mathrm{Si}_{15} \mathrm{~B}_{15} \mathrm{C}_{5}$ & 10.8 & 22.5 & 0.48 & 38 \\
\hline $\mathrm{Fe}_{65} \mathrm{Si}_{15} \mathrm{~B}_{15} \mathrm{C}_{5}$ & 6 & 23.1 & 0.26 & 38 \\
\hline $\mathrm{Fe}_{36} \mathrm{Co}_{40} \mathrm{~B}_{12.9} \mathrm{Si}_{11.1}$ & 19.8 & 23.9 & 0.83 & 25 \\
\hline $\mathrm{Co}_{67} \mathrm{Fe}_{3.85} \mathrm{Ni}_{1.45} \mathrm{~B}_{11.5} \mathrm{Si}_{14.5} \mathrm{Mo}_{1.7}$ & 6.6 & 15.7 & 0.42 & -3 \\
\hline $\mathrm{Co}_{67} \mathrm{Fe}_{3.85} \mathrm{Ni}_{1.45} \mathrm{~B}_{11.5} \mathrm{Si}_{14.5} \mathrm{Mo}_{1.7}$ & 6.8 & 13.6 & 0.5 & -3 \\
\hline $\mathrm{Co}_{67} \mathrm{Fe}_{3.85} \mathrm{Ni}_{1.45} \mathrm{~B}_{11.5} \mathrm{Si}_{14.5} \mathrm{Mo}_{1.7}$ & 9.8 & 18.5 & 0.53 & -3 \\
\hline $\mathrm{Co}_{67} \mathrm{Fe}_{3.85} \mathrm{Ni}_{1.45} \mathrm{~B}_{11.5} \mathrm{Si}_{14.5} \mathrm{Mo}_{1.7}$ & 11.8 & 18.4 & 0.64 & -3 \\
\hline $\mathrm{Co}_{67} \mathrm{Fe}_{3.85} \mathrm{Ni}_{1.45} \mathrm{~B}_{11.5} \mathrm{Si}_{14.5} \mathrm{Mo}_{1.7}$ & 13.4 & 20.9 & 0.64 & -3 \\
\hline $\mathrm{Co}_{67} \mathrm{Fe}_{3.85} \mathrm{Ni}_{1.45} \mathrm{~B}_{11.5} \mathrm{Si}_{14.5} \mathrm{Mo}_{1.7}$ & 16.8 & 24 & 0.7 & -3 \\
\hline $\mathrm{Co}_{67} \mathrm{Fe}_{3.85} \mathrm{Ni}_{1.45} \mathrm{~B}_{11.5} \mathrm{Si}_{14.5} \mathrm{Mo}_{1.7}$ & 16.8 & 21 & 0.8 & -3 \\
\hline $\mathrm{Fe}_{3.8} \mathrm{Co}_{65.4} \mathrm{Ni}_{1} \mathrm{~B}_{13.8} \mathrm{Si}_{13} \mathrm{Mo}_{1.35} \mathrm{C}_{1.65}$ & 18.8 & 22.2 & 0.85 & -1 \\
\hline $\mathrm{Co}_{69.2} \mathrm{Fe}_{3.6} \mathrm{Ni}_{1} \mathrm{~B}_{12.5} \mathrm{Si}_{11} \mathrm{Mo}_{1.5} \mathrm{C}_{1.2}$ & 22.8 & 23.2 & 0.98 & -0.3 \\
\hline $\mathrm{Fe}_{16} \mathrm{Co}_{60} \mathrm{Si}_{13} \mathrm{~B}_{11}$ & 12 & 29 & 0.4 & 15 \\
\hline $\mathrm{Co}_{41.7} \mathrm{Fe}_{36.4} \mathrm{Si}_{10.1} \mathrm{~B}_{11.8}$ & 13.6 & 34 & 0.4 & 25 \\
\hline $\mathrm{Co}_{41.7} \mathrm{Fe}_{36.4} \mathrm{Si}_{10.1} \mathrm{~B}_{11.8}$ & 18 & 38 & 0.47 & 25 \\
\hline $\mathrm{Co}_{41.7} \mathrm{Fe}_{36.4} \mathrm{Si}_{10.1} \mathrm{~B}_{11.8}$ & 13.6 & 24.6 & 0.55 & 25 \\
\hline $\mathrm{Fe}_{62} \mathrm{Ni}_{15.5} \mathrm{Si}_{7.5} \mathrm{~B}_{15}$ & 14.35 & 33.25 & 0.43 & 27 \\
\hline $\mathrm{Co}_{77.5} \mathrm{Si}_{15} \mathrm{~B}_{7.5}$ & 13.1 & 18 & 0.73 & -5 \\
\hline
\end{tabular}




\section{Magnetic Properties of as-Prepared Glass-Coated Microwires}

Magnetic properties of as-prepared microwires are reported elsewhere $[4,17,31,32]$. Therefore, we describe them very briefly. As described elsewhere $[4,17,31,32]$, perfectly rectangular hysteresis loops are observed in microwires with positive $\lambda_{s}(\mathrm{Fe}, \mathrm{Fe}-\mathrm{Co}$, and Fe-Ni based), while microwires with vanishing $\lambda_{s}$ present a completely different (linear and almost unhysteretic with low coercivity, $H_{\mathcal{C}}$ ) character of hysteresis loops (see Figure $4 \mathrm{~d}, \mathrm{e}$ ).

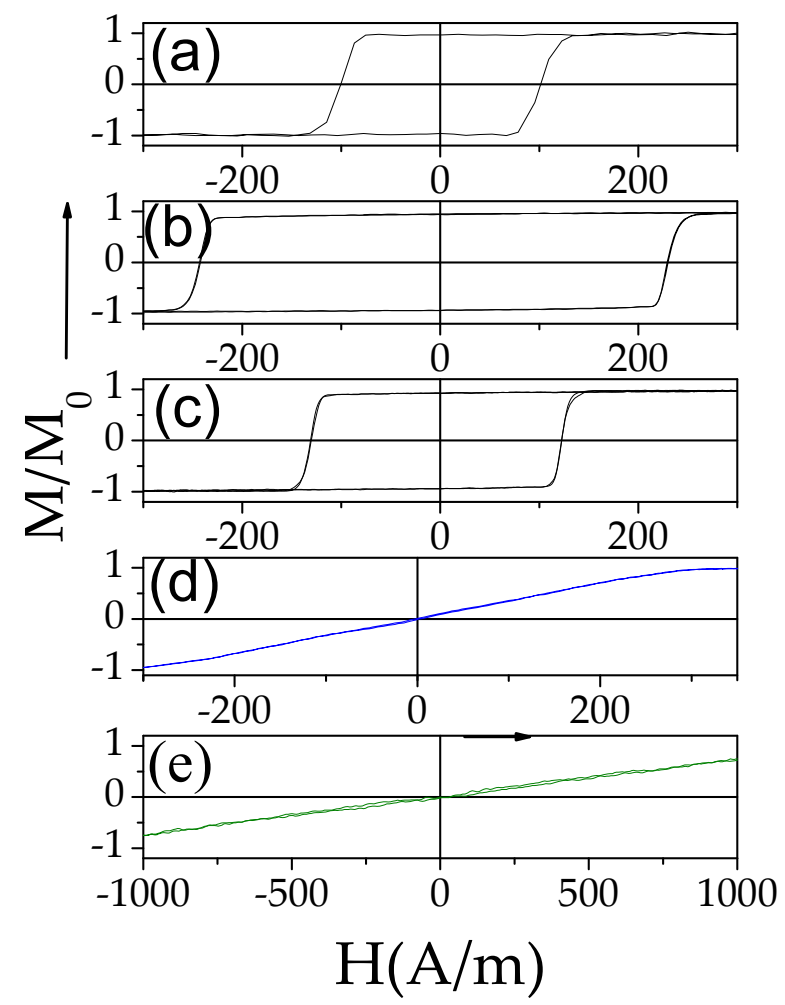

Figure 4. Hysteresis loops of amorphous magnetic microwires $\mathrm{Fe}_{75} \mathrm{~B}_{9} \mathrm{Si}_{12} \mathrm{C}_{4}\left(\lambda_{s}>0\right)$ (a), $\mathrm{Fe}_{36} \mathrm{Co}_{40} \mathrm{~B}_{12.9} \mathrm{Si}_{11.1}\left(\lambda_{s}>0\right)(\mathbf{b}), \mathrm{Fe}_{62} \mathrm{Ni}_{15.5} \mathrm{Si}_{7.5} \mathrm{~B}_{15}\left(\lambda_{s}>0\right)(\mathbf{c}), \mathrm{Co}_{67.1} \mathrm{Fe}_{3.8} \mathrm{Ni}_{1.4} \mathrm{Si}_{14.5} \mathrm{~B}_{11.5} \mathrm{Mo}_{1.7}\left(\lambda_{s} \approx 0\right.$, $\rho \approx 0.53)(\mathbf{d})$, and $\mathrm{Co}_{77.5} \mathrm{Si}_{15} \mathrm{~B}_{7.5}\left(\lambda_{s}<0\right)(\mathbf{e})$. Adapted from [45].

This correlation of the hysteresis loop character and $\lambda_{\mathrm{s}}$ values and sign are determined by the role of the magnetoelastic anisotropy, $K_{m e}$, given as $[4,41,42]$ :

$$
K_{m e} \approx 3 / 2 \lambda_{s} \sigma
$$

where $\sigma=\sigma_{i}+\sigma_{\text {app }}$ is the total stress, $\sigma_{i}$ is the total internal stress, and $\sigma_{\text {app }}$ is the applied stress.

Accordingly, the easiest way to tune the shape of hysteresis loops is by modifying the chemical composition of metallic nucleus.

The character of hysteresis loops is intrinsically related to the domain structure of microwires, which is affected not only by $\lambda_{s}$ value and sign, but also by the internal stress distribution and by the shape magnetic anisotropy $[73,74]$. Thus, the axial magnetization alignment in the core of thin magnetic wires is determined by the shape anisotropy [74]. However, the presence of strong internal stresses in Co-rich magnetic microwires with $\lambda_{s}<$ 0 turns the magnetization to a circumferential direction $[44,45,73-75]$. Accordingly, low $H_{c}$ (about 4-5 A/m) and almost linear hysteresis loops of Co-rich glass-coated microwires with low and negative $\lambda_{s}$ must be attributed to the remagnetization mechanism by magnetization rotation (see Figure $4 \mathrm{~d}, \mathrm{e}$ ). In these microwires with internal stresses of preferentially axial origin, the $\sigma_{i}$ value can be modified by the $\rho$-ratio (see Equation (4)). Accordingly, circumferential anisotropy of such $\mathrm{Co}$-rich microwires can be tuned by $\rho$-ratio: magnetic 
anisotropy field, $H_{k}$, can be represented as a function of $\rho$-ratio (see Figure $5 \mathrm{a}, \mathrm{b}$ ). Proof of this interpretation is the dependence of the hysteresis loops of $\mathrm{Co}_{65.4} \mathrm{Fe}_{3.8} \mathrm{Ni}_{1} \mathrm{~B}_{13.8} \mathrm{Si}_{13} \mathrm{Mo}_{1.35} \mathrm{C}_{1.65}$ microwire on $\sigma_{a p p}$ : qualitatively, the same type of $H_{k}\left(\sigma_{a p p}\right)$ dependence (showing an increase in $H_{k}$ under the effect of tensile applied stress, $\left.\sigma_{\text {app }}\right)$ is observed (see Figure $5 c$ ).
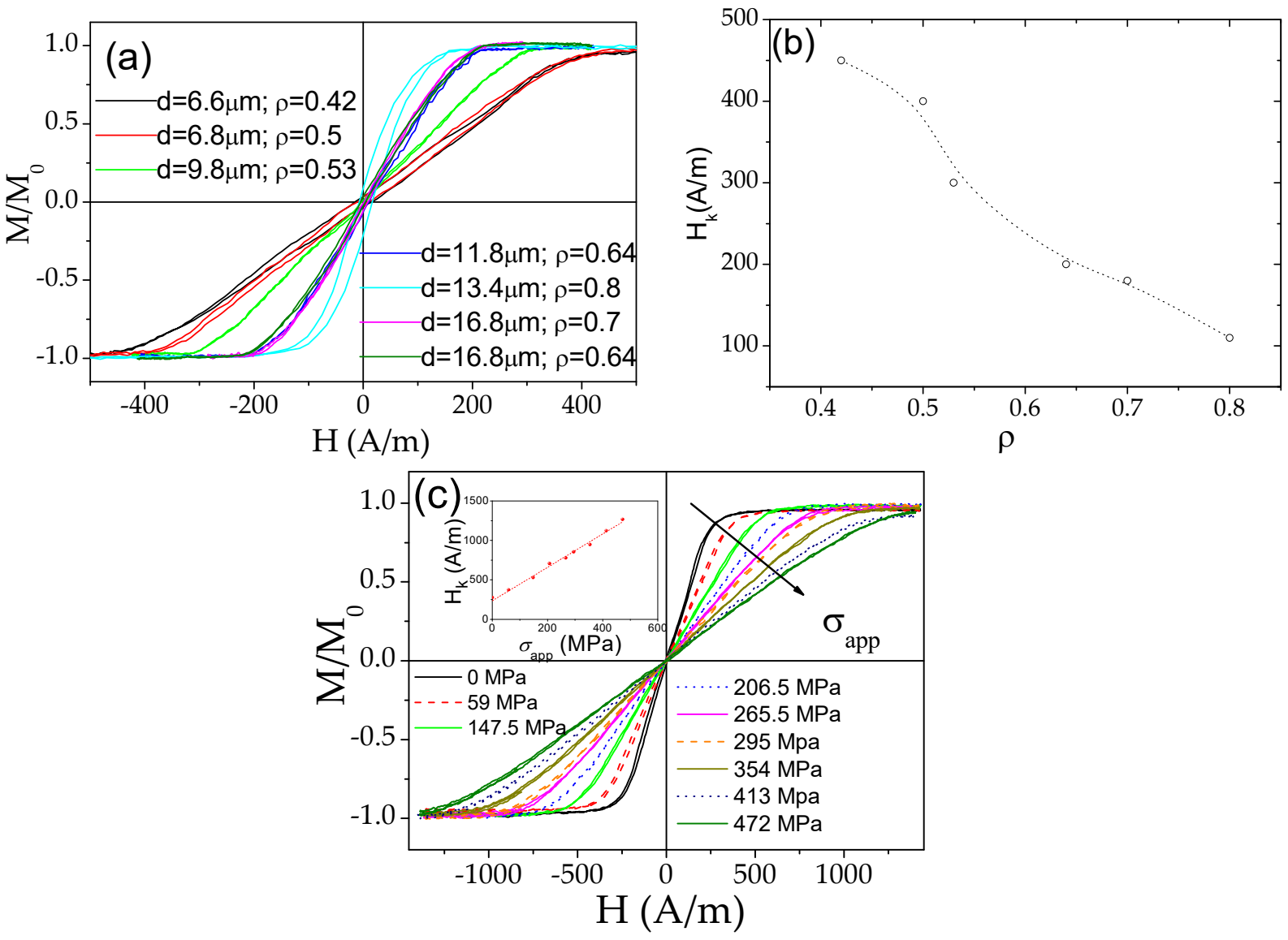

Figure 5. Hysteresis loops of $\mathrm{Co}_{67.1} \mathrm{Fe}_{3.8} \mathrm{Ni}_{1.4} \mathrm{Si}_{14.5} \mathrm{~B}_{11.5} \mathrm{Mo}_{1.7}$ microwires with different $\rho$-ratio (a), $H_{k}(\rho)$ dependence for the same microwires (b), and effect of applied stress on hysteresis loop of $\mathrm{Co}_{65.4} \mathrm{Fe}_{3.8} \mathrm{Ni}_{1} \mathrm{~B}_{13.8} \mathrm{Si}_{13} \mathrm{Mo}_{1.35} \mathrm{C}_{1.65}$ microwire. $H_{k}\left(\sigma_{\text {app }}\right)$ dependence is shown by the inset in (c). Reproduced with permission from $[75,76]$.

Observed decrease in $H_{k}$ values by increasing the $\rho$-ratio must be attributed to decreased internal stresses of preferentially axial stress. However, simultaneously with a decrease in $H_{k}$ an increase in $H_{c}$ is observed (see Figure 5a,c). To explain the observed increase in $H_{c}$ we must consider a remarkable magnetic hardening upon annealing, observed in various Co-rich glass-coated microwires with vanishing $\lambda_{s}[68,70,72]$. Similarly, transformation of almost anhysteretic loops into almost perfectly rectangular and, hence, $H_{c}$ increase is also observed upon gradual glass-coating removal by chemical etching in Co-rich microwires [75]. This unexpected magnetic hardening has been explained considering either magnetostriction coefficient change induced by relaxation of the internal stresses or just an increase in the volume of inner axially magnetized core originating from the counterbalance between the magnetoelastic and shape anisotropies [68,70-75]. In the present case, a decrease in $\sigma_{a p p}$ must affect the hysteresis loops in the similar way as the relaxation of the partial stresses. Therefore, an increase in $H_{c}$ is expected.

Completely different hysteresis loops are reported for Fe-rich microwires (see Figure $6 \mathrm{a}-\mathrm{c}$ ); perfectly rectangular hysteresis loops are reported for as-prepared microwires with $\lambda_{s}>0$ (Fe, Fe-Co, and Fe-Ni rich microwires) $[17,45,75]$. For Fe-rich microwires of the same composition $\left(\mathrm{Fe}_{70} \mathrm{~B}_{15} \mathrm{Si}_{10} \mathrm{C}_{5}\right)$, an increase in $H_{c}$ is observed with a decrease in the $\rho$-ratio (i.e., with an increase in the $\sigma_{i}$ value) (see Figure 6). Similar to Co-rich microwires, 
$H_{c}$ can be represented as a function of $\rho$-ratio (see Figure $6 \mathrm{~b}$ ). Moreover, modification of hysteresis loops under applied tensile stress shown in Figure $6 \mathrm{c}$ has the same tendency as the influence of $\rho$-ratio; an increase in $H_{c}$ upon $\sigma_{\text {app }}$ is observed.
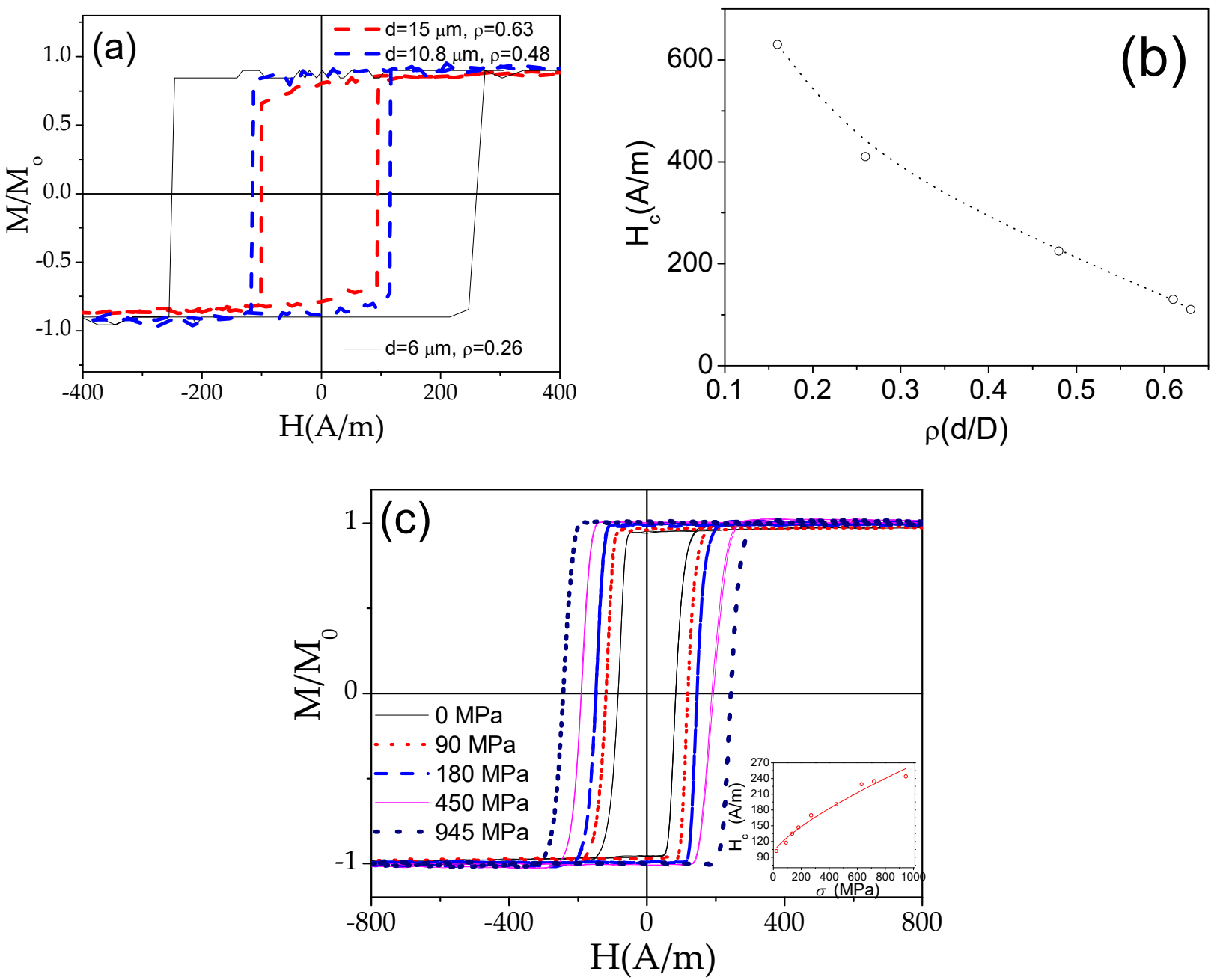

Figure 6. Hysteresis loops of $\mathrm{Fe}_{70} \mathrm{~B}_{15} \mathrm{Si}_{10} \mathrm{C}_{5}$ microwires with different $\rho$-ratio $(\mathbf{a}), H_{c}(\rho)$ dependence for the same microwires (b), and effect of applied stress on the hysteresis loop of $\mathrm{Fe}_{75} \mathrm{~B}_{9} \mathrm{Si}_{12} \mathrm{C}_{4}$ microwire. $H_{c}\left(\sigma_{\text {app }}\right)$ dependence is shown by the inset in $(\mathbf{c})$. Plots $(\mathbf{a}, \mathbf{b})$ are adapted from [75] and (c) is reproduced with permission from [76].

As shown in Figure 6a,b, in such Fe-rich microwires with perfectly rectangular hysteresis loops, a change in the $\rho$-ratio allows one to substantially change $H_{c}$ (from 85 to $250 \mathrm{~A} / \mathrm{m})$.

Similarly, to the case of Co-rich microwires, the $H_{c}$ values for different $D$ and $d$ values can be represented as the $H_{c}(\rho)$ dependence (see Figure $6 \mathbf{b}$ ).

An increase in $H_{c}$ upon applied tensile stresses, $\sigma$, observed in Fe-rich microwires, was interpreted considering the energy required to form the domain wall involved in the bistable magnetization process [76]. This approach suggests $H_{\mathcal{C}} \sim \sigma^{1 / 2}$, which is roughly experimentally observed for Fe-rich microwires [76]. A decrease in $H_{c}$ upon increase of $\rho$-ratio (see Figure 6b) must be attributed to a decrease in $\sigma_{i}$ magnitude.

As expected from the results provided above on the correlation of hysteresis loops and the $\rho$-ratio, $\Delta Z / Z(H)$ dependencies of Co-rich microwires are affected by $\rho$-ratio (see Figure 7a). Similar correlation of $\Delta Z / Z(H)$ dependencies and the $\rho$-ratio (reflecting the $\sigma_{i}$ value) has been previously reported elsewhere for various Co-rich microwires [31,32,68-70,77]. Compared to Co-rich microwires with vanishing $\lambda_{s}$ values, $\Delta Z / Z$ values that are quite low (an order 
of magnitude less) are reported for as-prepared microwires with $\lambda_{s}>0$ (see Figure $7 \mathrm{~b}$ ). Therefore, from the viewpoint of GMI applications, as-prepared microwires with $\lambda_{s}>0$ (Fe, $\mathrm{Fe}-\mathrm{Co}$, and $\mathrm{Fe}-\mathrm{Ni}$ rich microwires) are usually not considered.
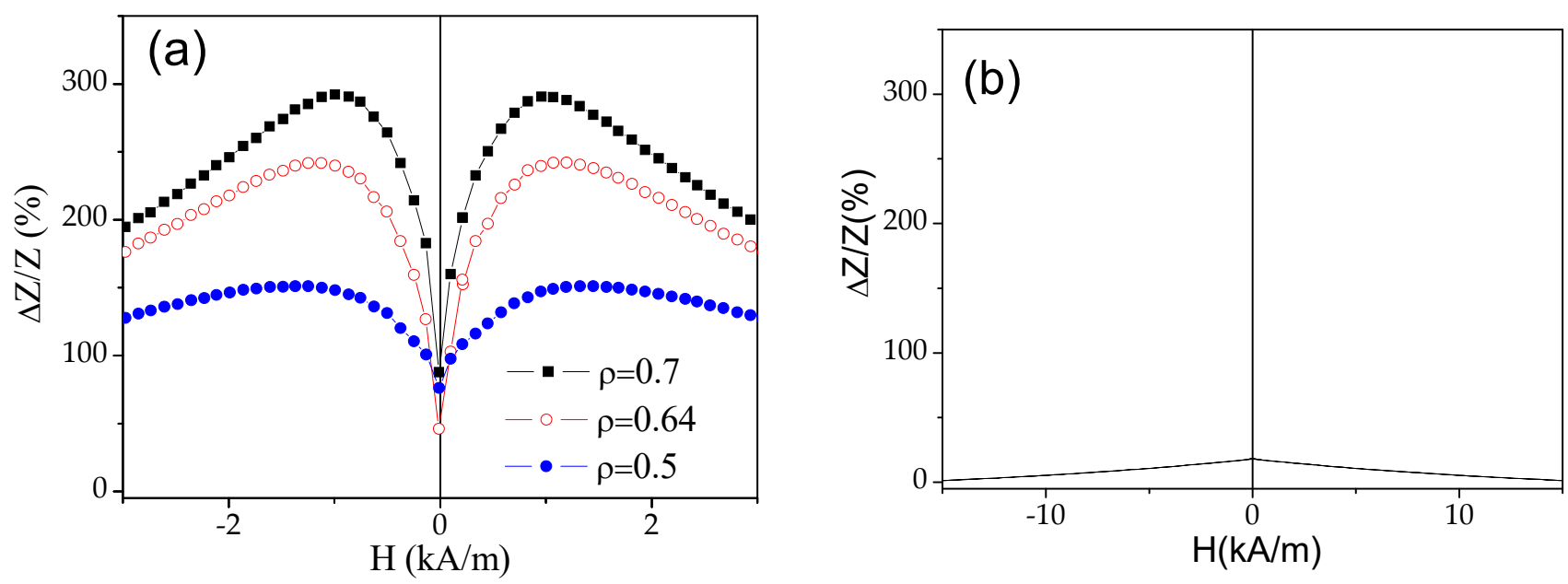

Figure 7. $\Delta \mathrm{Z} / \mathrm{Z}(\mathrm{H})$ dependencies of as-prepared $\mathrm{Co}_{67} \mathrm{Fe}_{3.85} \mathrm{Ni}_{1.45} \mathrm{~B}_{11.5} \mathrm{Si}_{14.5} \mathrm{Mo}_{1.7}$ microwires with different $\rho$-ratios (a) and $\mathrm{Fe}_{75} \mathrm{~B}_{9} \mathrm{Si}_{12} \mathrm{C}_{4}$ microwire (b) measured at $500 \mathrm{MHz}$. Plot (a) is reproduced with permission from [31] and (b)with permission from [77].

However, in as-prepared microwires with $\lambda_{s}>0$ (Fe, Fe-Co and Fe-Ni rich microwires) with perfectly rectangular hysteresis loops, the remagnetization process runs by fast single DW propagation [78-81].

The evident correlation of magnetic properties and $\sigma_{i}$ (modified through the $\rho$-ratio) is limited by various factors. Thus, the insulating glass coating with relatively low thermal conductivity can affect the quenching rate. Accordingly, microwires with sufficiently thick glass coating may present either crystalline or mixed crystalline-amorphous structures and, hence, rather different magnetic properties [56]. On the other hand, for sufficiently thin glass coating, the $\sigma_{i t}$ can be of the same order as $\sigma_{i q}$ and $\sigma_{i d}\left(\sigma_{i t} \sim \sigma_{i q} \sim \sigma_{i d}\right)$. Accordingly, such correlation may be broken.

\section{Tuning of Magnetic Softness and GMI Effect in Amorphous Microwires}

As shown above, hysteresis loops and GMI effect are substantially affected not only by chemical composition of microwires, but also by their geometry ( $\rho$-ratio). Therefore, obviously, for a comparative analysis on the effect of post-processing, we need to fix the composition and geometry of the microwire. Accordingly, we selected two typical Co- and Fe-rich microwires with fixed chemical composition and geometry, and provide comparative analysis for the selected microwires.

\subsection{Tailoring of Magnetic Properties and GMI Effect in Co-Rich Amorphous Microwires}

As shown above, internal stress (magnitude and spatial distribution) is one of the main factors affecting magnetic properties of glass-coated microwires. Thermal treatment is the most traditional method for internal stress relaxation. However, after conventional furnace annealing at sufficiently high temperature the hysteresis loop shape of Co-rich microwires with vanishing $\lambda_{s}$ usually turns into rectangular [82,83].

As discussed above, hysteresis loops and GMI effect of Co-rich microwires are substantially affected not only by the chemical composition, but also by the geometry. Therefore, for comprehensive analysis of the influence of post-processing on magnetic properties, we selected just one typical Co-rich microwire: $\mathrm{Co}_{69.2} \mathrm{Fe}_{3.6} \mathrm{Ni}_{1} \mathrm{~B}_{12.5} \mathrm{Si}_{11} \mathrm{Mo}_{1.5} \mathrm{C}_{1.2}(d=22.8 \mu \mathrm{m}$, $D=23.2 \mu \mathrm{m})$.

Similar to other Co-rich microwires, considerable magnetic hardening is observed upon conventional annealing: all annealed samples at $250{ }^{\circ} \mathrm{C} \leq T_{\text {ann }} \leq 350{ }^{\circ} \mathrm{C}\left(t_{\text {ann }}=60 \mathrm{~min}\right)$ 
present considerable magnetic hardening. Hysteresis loops of annealed samples turn to rectangular; a remarkable increase in $H_{c}$ (from 4 up to $90 \mathrm{~A} / \mathrm{m}$ ) and remanent magnetization, $M_{r} / M_{0}$, upon annealing is observed (see Figure 8a). Finally, an almost perfectly rectangular hysteresis loop is observed for the sample annealed at $T_{a n n} \geq 350{ }^{\circ} \mathrm{C}\left(t_{a n n}=60 \mathrm{~min}\right)$.
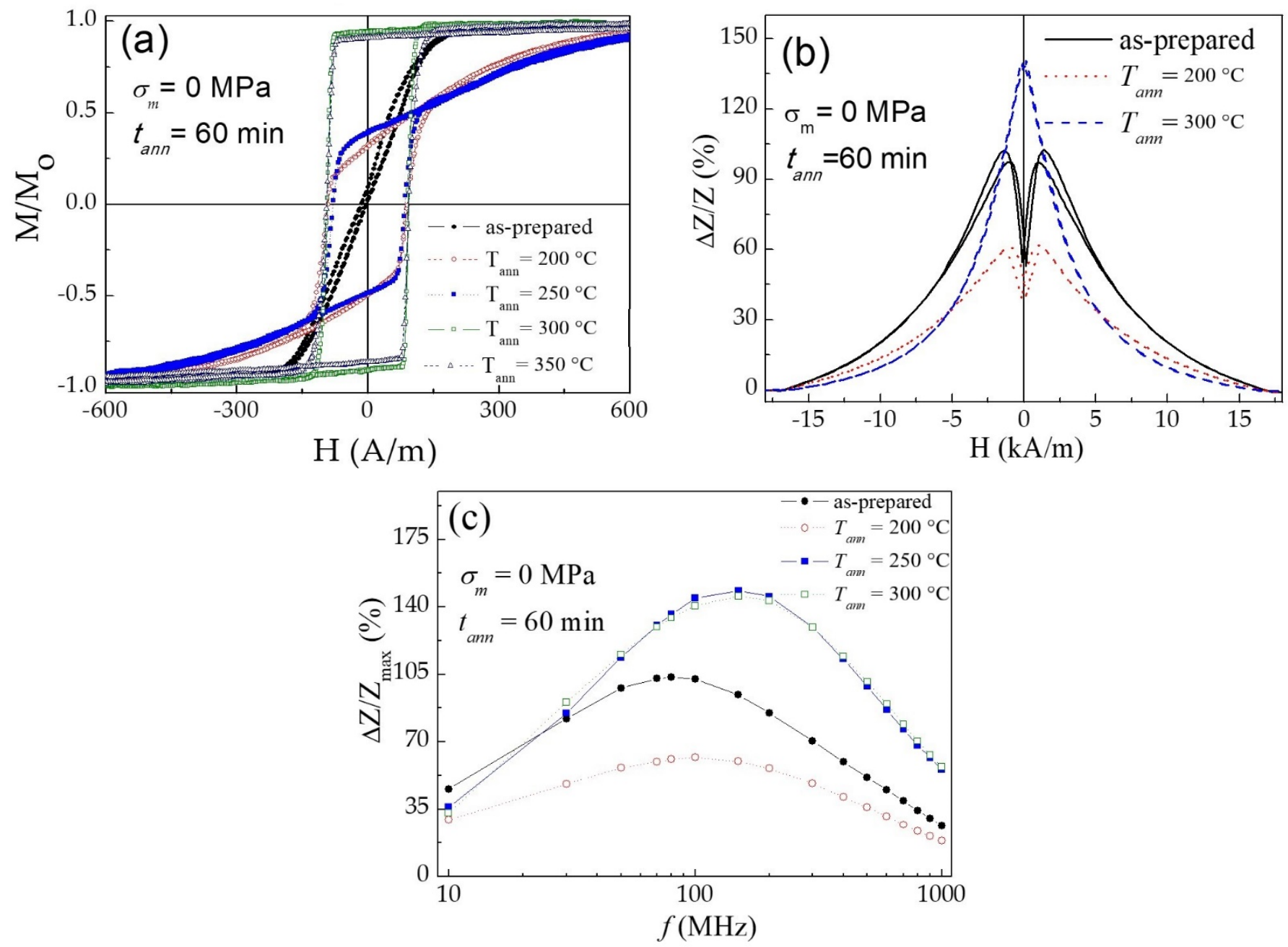

Figure 8. Hysteresis loop (a) $\Delta Z / Z(H)$ dependencies, measured at $100 \mathrm{MHz}$ (b) and frequency dependence of maximum GMI ratio, $\Delta Z / Z_{\max }(\mathbf{c})$ of as-prepared and annealed at different temperatures $\mathrm{Co}_{69.2} \mathrm{Fe}_{3.6} \mathrm{Ni}_{1} \mathrm{~B}_{12.5} \mathrm{Si}_{11} \mathrm{Mo}_{1.5} \mathrm{C}_{1.2}$ microwire. Adapted from [83].

A decrease in the maximum GMI ratio, $\Delta Z / Z_{\max }$, is observed after annealing at $T_{a n n}=200{ }^{\circ} \mathrm{C}$, while an increase in the $\Delta Z / Z_{\max }$ is observed at higher $T_{\text {ann }}$ (see Figure $8 \mathrm{~b}, \mathrm{c}$ ). The character of $\Delta Z / Z(H)$ dependence gradually changes after annealing from double peak (for as-prepared microwire) to single peak (with $\Delta Z / Z_{\max }$ at $H=0$ ) (see Figure $8 \mathrm{~b}$ ).

As observed elsewhere [83,84], magnetic hardening can be suppressed by stressannealing. The stress-annealing induced anisotropy is affected by several parameters, such as $T_{a n n}$ and $\sigma_{m} ;$ after stress-annealing at moderate $T_{a n n}$ and $\sigma_{m}$ a decrease in $H_{c}$ and increase in $M_{r} / M_{o}$ are observed (see Figure 9a). At higher $T_{a n n}$, however, while a decrease in $H_{c}$ is still observed with increasing $\sigma_{m}, M_{r} / M_{o}$ begins to also decrease with increasing $\sigma_{m}$ (see Figure $9 b, c$ ). Accordingly, magnetic softness of stress-annealed at sufficiently high $T_{\text {ann }}$ and $\sigma_{m} \mathrm{Co}_{69.2} \mathrm{Fe}_{3.6} \mathrm{Ni}_{1} \mathrm{~B}_{12.5} \mathrm{Si}_{11} \mathrm{Mo}_{1.5} \mathrm{C}_{1.2}$ microwire can be substantially improved; $H_{c} \approx 14 \mathrm{~A} / \mathrm{m}$ and $H_{k} \approx 50 \mathrm{~A} / \mathrm{m}$ are observed for the sample stress-annealed at $T_{\text {ann }}=300{ }^{\circ} \mathrm{C}$ and $\sigma_{m}=472 \mathrm{MPa}$. Even better magnetic softness: $H_{c} \approx 2 \mathrm{~A} / \mathrm{m}$ and $H_{k} \approx 50 \mathrm{~A} / \mathrm{m}$ and $M_{r} / M_{o} \approx 0$ have been obtained for $\mathrm{Co}_{69.2} \mathrm{Fe}_{3.6} \mathrm{Ni}_{1} \mathrm{~B}_{12.5} \mathrm{Si}_{11} \mathrm{Mo}_{1.5} \mathrm{C}_{1.2}$ microwire stressannealed at $T_{\text {ann }}=350{ }^{\circ} \mathrm{C}$ and $\sigma_{m}=472 \mathrm{MPa}$ (see Figure 9c). 

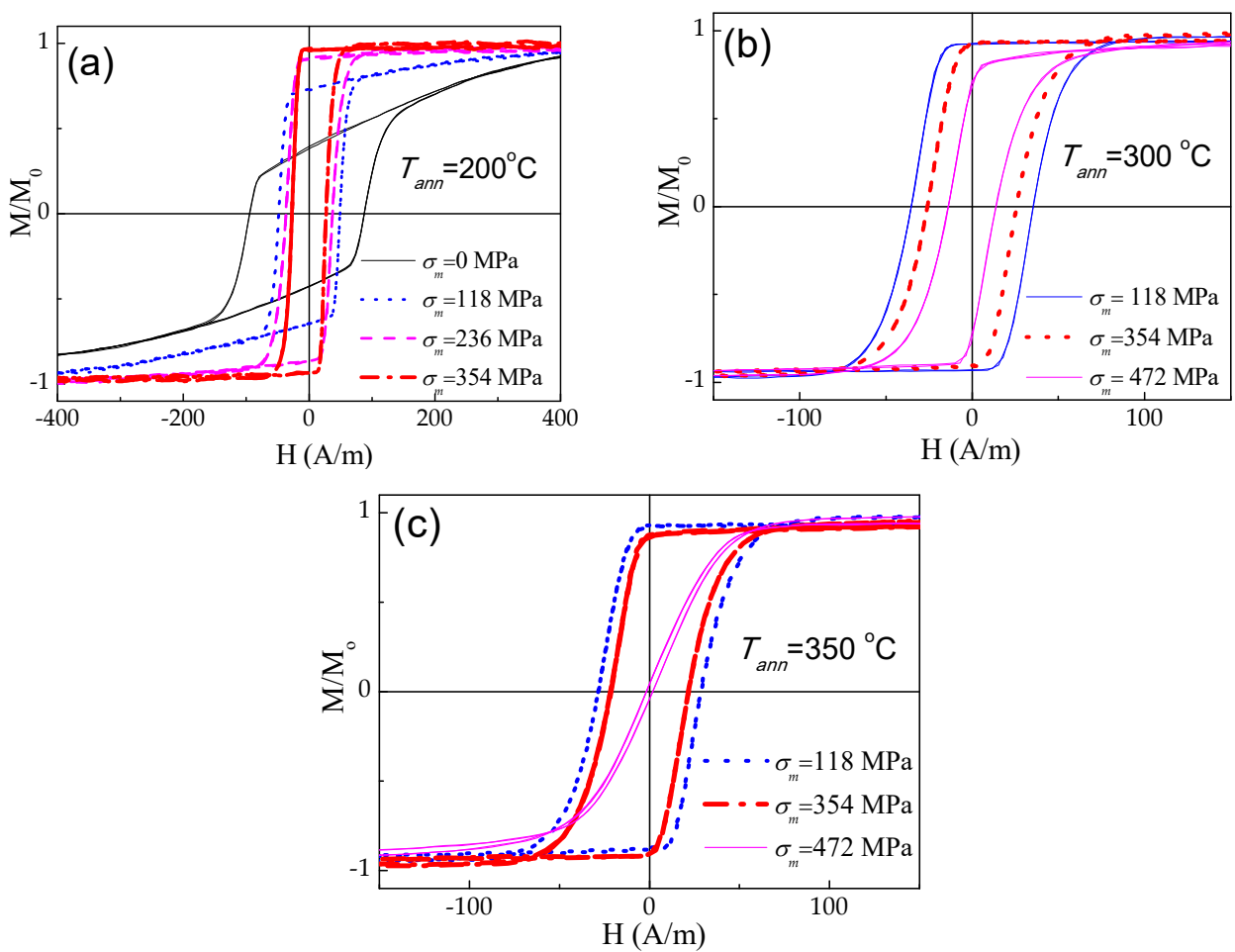

Figure 9. Hysteresis loops of $\mathrm{Co}_{69.2} \mathrm{Fe}_{3.6} \mathrm{Ni}_{1} \mathrm{~B}_{12.5} \mathrm{Si}_{11} \mathrm{Mo}_{1.5} \mathrm{C}_{1.2}$ microwires annealed and stressannealed at $T_{a n n}=200{ }^{\circ} \mathrm{C}(\mathbf{a})$, stress-annealed at $T_{a n n}=300{ }^{\circ} \mathrm{C}(\mathbf{b})$, and stress-annealed at $T_{a n n}=350{ }^{\circ} \mathrm{C}$ (c) at different $\sigma_{\text {app }}$. Adapted from [84].

The influence of both $T_{a n n}$ and $\sigma_{m}$ on hysteresis loops is illustrated in Figure 10; almost identical properties have been obtained in $\mathrm{Co}_{69.2} \mathrm{Fe}_{3.6} \mathrm{Ni}_{1} \mathrm{~B}_{12.5} \mathrm{Si}_{11} \mathrm{Mo}_{1.5} \mathrm{C}_{1.2}$ microwires stress-annealed at different $T_{a n n}$ and $\sigma_{m}$. Thus, $H_{c} \approx 14 \mathrm{~A} / \mathrm{m}$ and $H_{k} \approx 50 \mathrm{~A} / \mathrm{m}$ have been obtained in the $\mathrm{Co}_{69.2} \mathrm{Fe}_{3.6} \mathrm{Ni}_{1} \mathrm{~B}_{12.5} \mathrm{Si}_{11} \mathrm{Mo}_{1.5} \mathrm{C}_{1.2}$ microwires stress-annealed at $\mathrm{T}_{\text {ann }}=300{ }^{\circ} \mathrm{C}$, $\sigma_{m}=472 \mathrm{MPa}$ and $\mathrm{T}_{a n n}=375^{\circ} \mathrm{C}, \sigma_{m}=354 \mathrm{MPa}$.

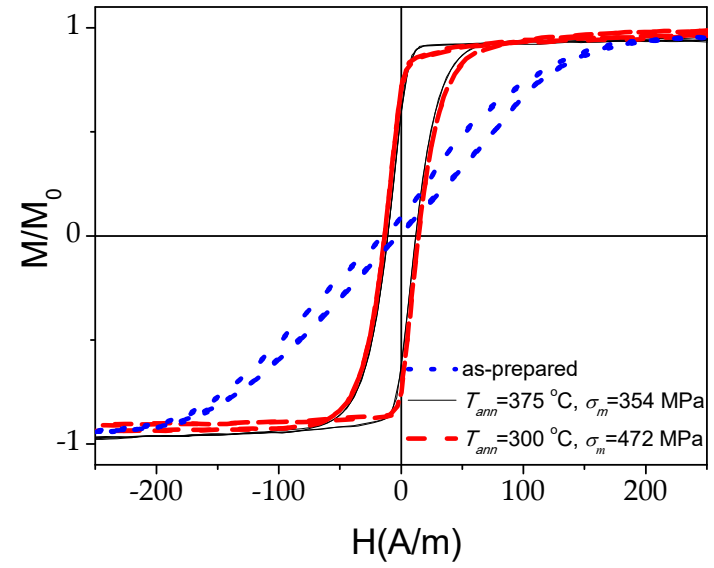

Figure 10. Hysteresis loops of as-prepared and stress-annealed at $T_{a n n}=300{ }^{\circ} \mathrm{C}, \sigma_{m}=472 \mathrm{MPa}$, and $T_{a n n}=375{ }^{\circ} \mathrm{C}, \sigma_{m}=354 \mathrm{MPa} \mathrm{Co}_{69.2} \mathrm{Fe}_{3.6} \mathrm{Ni}_{1} \mathrm{~B}_{12.5} \mathrm{Si}_{11} \mathrm{Mo}_{1.5} \mathrm{C}_{1.2}$ microwires. Reproduced with permission from [84].

Accordingly, substantial GMI performance improvement was achieved in properly stressannealed $\mathrm{Co}_{69.2} \mathrm{Fe}_{3.6} \mathrm{Ni}_{1} \mathrm{~B}_{12.5} \mathrm{Si}_{11} \mathrm{Mo}_{1.5} \mathrm{C}_{1.2}$ microwires; $\Delta \mathrm{Z} / \mathrm{Z}_{\text {max }} \geq 200 \%$ is observed in all stressannealed (at $\sigma_{m}=472 \mathrm{MPa}$ ) $\mathrm{Co}_{69.2} \mathrm{Fe}_{3.6} \mathrm{Ni}_{1} \mathrm{~B}_{12.5} \mathrm{Si}_{11} \mathrm{Mo}_{1.5} \mathrm{C}_{1.2}$ microwires (see Figure $11 \mathrm{a}, \mathrm{b}$ ). These $\Delta Z / Z_{\max }$ values are almost twice those for as-prepared $\mathrm{Co}_{69.2} \mathrm{Fe}_{3.6} \mathrm{Ni}_{1} \mathrm{~B}_{12.5} \mathrm{Si}_{11} \mathrm{Mo}_{1.5} \mathrm{C}_{1.2} \mathrm{mi}$ crowires (see Figure 11c). 

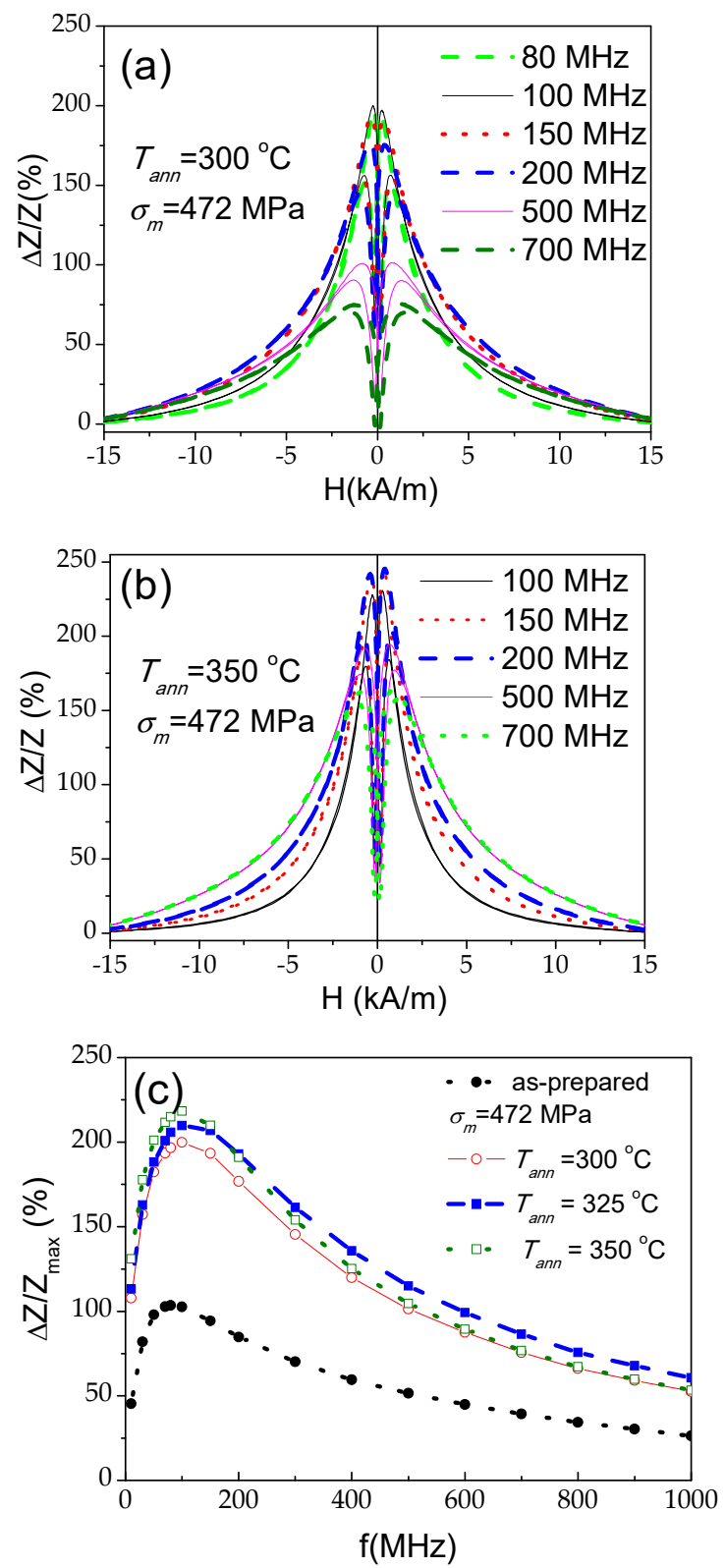

Figure 11. $\Delta \mathrm{Z} / \mathrm{Z}(H)$ dependencies of stress-annealed $\left(\sigma_{m}=472 \mathrm{MPa}\right)$ measured at different frequencies for $T_{\text {ann }}=300{ }^{\circ} \mathrm{C}(\mathbf{a}), T_{a n n}=350{ }^{\circ} \mathrm{C}(\mathbf{b}), \Delta Z / Z_{\text {max }}(f)$ dependencies for as-prepared and stress-annealed $\mathrm{Co}_{69.2} \mathrm{Fe}_{3.6} \mathrm{Ni}_{1} \mathrm{~B}_{12.5} \mathrm{Si}_{11} \mathrm{Mo}_{1.5} \mathrm{C}_{1.2}$ microwires (c). Reproduced with permission from [84].

The frequency, $f_{m}$, at which the highest $\Delta Z / Z_{\max }$ value is observed in $\Delta Z / Z_{\max }(f)$ dependence for as-prepared $\mathrm{Co}_{69.2} \mathrm{Fe}_{3.6} \mathrm{Ni}_{1} \mathrm{~B}_{12.5} \mathrm{Si}_{11} \mathrm{Mo}_{1.5} \mathrm{C}_{1.2}$ microwire is at about $80 \mathrm{MHz}$ $\left(\Delta Z / Z_{\text {max }} \approx 100 \%\right)$. However, in stress-annealed samples $\Delta Z / Z_{\max } \approx 220 \%$ are observed at $f_{m} \approx 150 \mathrm{MHz}$ (see Figure 11c). The $\Delta Z / Z(H)$ dependence character is also affected by stress-annealing; a double peak $\Delta Z / Z(H)$ dependence is observed in stress-annealed $\mathrm{Co}_{69.2} \mathrm{Fe}_{3.6} \mathrm{Ni}_{1} \mathrm{~B}_{12.5} \mathrm{Si}_{11} \mathrm{Mo}_{1.5} \mathrm{C}_{1.2}$ microwires (see Figure 11a,b). However, the maximum in the $\Delta Z / Z(H)$ dependence is observed at a magnetic field, $H_{m}$, lower than that of the as-prepared $\mathrm{Co}_{69.2} \mathrm{Fe}_{3.6} \mathrm{Ni}_{1} \mathrm{~B}_{12.5} \mathrm{Si}_{11} \mathrm{Mo}_{1.5} \mathrm{C}_{1.2}$ microwire. This difference must be explained considering that $H_{m}$ is linked to the magnetic anisotropy field [28-30].

The origin of induced magnetic anisotropy in amorphous materials is commonly attributed either to directional atomic pair ordering (chemical or topological), structural anisotropy, or "back stresses" [85-89]. This magnetic anisotropy can be induced either by stress or by magnetic field annealing [85-89]. Weak circumferential magnetic anisotropy is considered as one of the prerequisites for achievement of high GMI effect [28-30]. Therefore, 
Joule heating, allowing annealing due to the heat generated by the electrical current in the presence of a circumferential magnetic field, $H_{\text {circ }}$, created by the current, is considered among the alternative methods for GMI effect tuning in amorphous materials [66,90-94].

One of the problems related to Joule heating is reliable determination of the sample temperature. In most cases the sample temperature is determined by indirect methods. Thus, one of the most relevant parameters of Joule heating treatment is the current density [95]. In conventional amorphous materials (ribbons and amorphous wires prepared by in-rotating water method), the current density, $j$, of 30-45 A/mm $\mathrm{mm}^{2}$ produced heating up to $400{ }^{\circ} \mathrm{C}$ [95]. However, in glass-coated microwires the heat exchange is affected by thermal conductivity of glass coating, by microwire diameter. Accordingly, recent estimations considering convection and radiation heat exchange along with the experimental results (i.e., control of resistivity) show that the crystallization of a glass-coated microwire is observed at $j>200 \mathrm{~A} / \mathrm{mm}^{2}$ [94,96]. However, DC and even pulsed currents, $I$, of $50 \mathrm{~mA}$ can produce irreversible changes in GMI effect related to Joule heating [97]. Accordingly, for studies of the effect of Joule heating on GMI effect and magnetic softness of $\mathrm{Co}_{69.2} \mathrm{Fe}_{3.6} \mathrm{Ni}_{1} \mathrm{~B}_{12.5} \mathrm{Si}_{11} \mathrm{Mo}_{1.5} \mathrm{C}_{1.2}$ microwire, we used $I=24$ and $32 \mathrm{~mA}$, which correspond to $j \approx 58$ and $78 \mathrm{~A} / \mathrm{mm}^{2}$, respectively [93]. These $I$ and $j$ values are selected to avoid crystallization and related deterioration of magnetic properties.

Unlike conventional furnace annealing, under Joule heating (at $I=32 \mathrm{~mA}$ ) the hysteresis loops of the $\mathrm{Co}_{69.2} \mathrm{Fe}_{3.6} \mathrm{Ni}_{1} \mathrm{~B}_{12.5} \mathrm{Si}_{11} \mathrm{Mo}_{1.5} \mathrm{C}_{1.2}$ microwire remain linear (see Figure 12). However, some decrease in $H_{k}$, was observed (see Figure 12 inset).

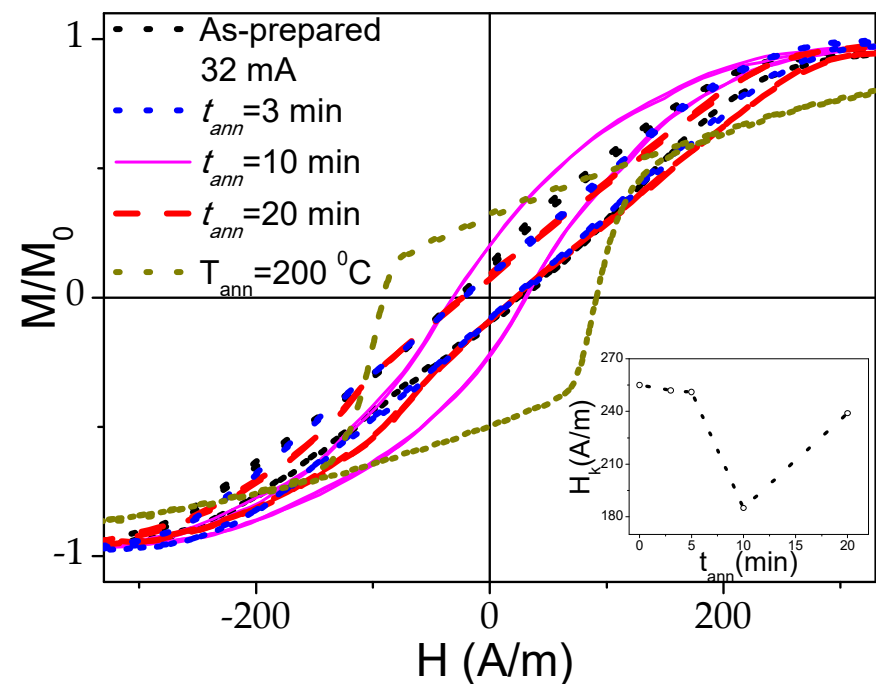

Figure 12. Hysteresis loops of as-prepared samples that were Joule heated at $32 \mathrm{~mA}$ and annealed at $200{ }^{\circ} \mathrm{C}$ for $60 \mathrm{~min} . H_{k}\left(t_{a n n}\right)$ dependence evaluated from the hysteresis loops is shown in the inset. Reproduced with permission from [93].

Accordingly, the relevant advantage of Joule heating treatment is that it allows for preventing the magnetic hardening observed upon conventional furnace annealing of Co-rich microwires with vanishing $\lambda_{s}$ [83]. As observed in Figure 13, a remarkable increase in $\Delta Z / Z_{\max }$ is observed in Joule heated samples.

An increase in $\Delta Z / Z_{\max }$ from $\Delta Z / Z_{\max } \approx 100 \%$ up to $\Delta Z / Z_{\max } \approx 300 \%$ (for $I=24$ and $32 \mathrm{~mA}, t_{\text {ann }}=10 \mathrm{~min}$ ) is achieved by Joule heating of $\mathrm{Co}_{67} \mathrm{Fe}_{3.9} \mathrm{Ni}_{1.4} \mathrm{~B}_{11.5} \mathrm{Si}_{14.5} \mathrm{Mo}_{1.6}$ microwire (see Figures 13 and 14). 

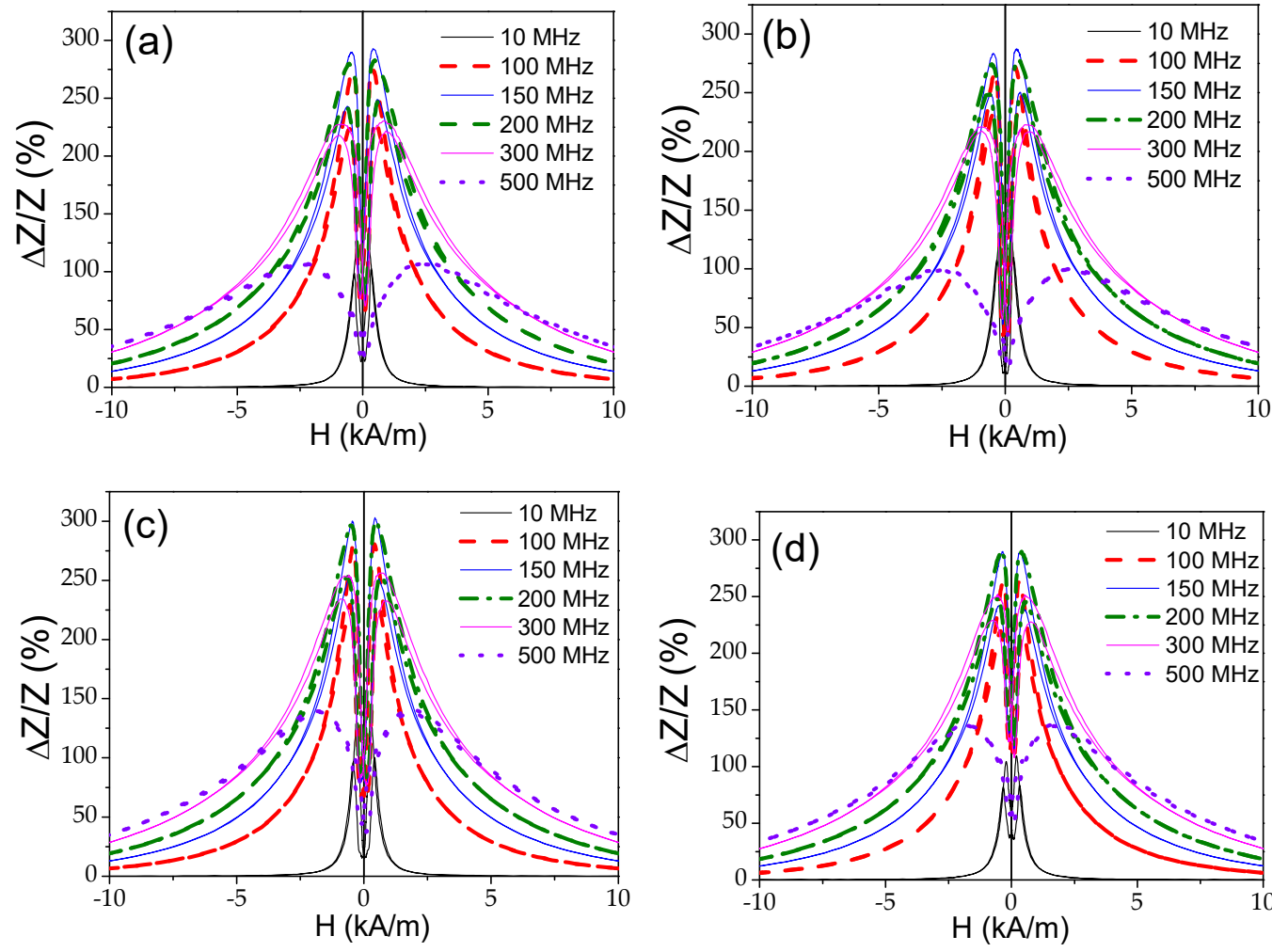

Figure 13. $\Delta Z / Z(H)$ dependencies measured at different $f$ for as-prepared and Joule heated at $32 \mathrm{~mA}$ for 3 (a), 5 (b), 10 (c), and $20 \mathrm{~min}(\mathbf{d}) \mathrm{Co}_{67} \mathrm{Fe}_{3.9} \mathrm{Ni}_{1.4} \mathrm{~B}_{11.5} \mathrm{Si}_{14.5} \mathrm{Mo}_{1.6}$ microwire. Adapted from [93].

From a comparison of $\Delta Z / Z_{\max }$ values we must emphasize that both stress-annealing and Joule heating allows a remarkable $\Delta Z / Z_{\max }$ improvement. In frequencies up to the $f=400-500 \mathrm{MHz}$ range, the highest $\Delta Z / Z_{\max }$ values are observed in Joule heated $\mathrm{Co}_{67} \mathrm{Fe}_{3.9} \mathrm{Ni}_{1.4} \mathrm{~B}_{11.5} \mathrm{Si}_{14.5} \mathrm{Mo}_{1.6}$ microwire, while for $f \geq 600 \mathrm{MHz}$, higher $\Delta \mathrm{Z} / \mathrm{Z}_{\text {max }}$ values are observed in stress-annealed $\mathrm{Co}_{67} \mathrm{Fe}_{3.9} \mathrm{Ni}_{1.4} \mathrm{~B}_{11.5} \mathrm{Si}_{14.5} \mathrm{Mo}_{1.6}$ microwire.

The origin of the magnetic field annealing induced anisotropy is commonly discussed in terms of the preferred magnetization orientation during the annealing [86-89,98-100].

In the present case, the internal stress relaxation may be responsible for the domain structure transformation related to an increase in the volume of the inner axially magnetized core upon annealing. Indeed, the origin of core-shell domain structure of magnetic wires is commonly attributed to the counterbalance of the magnetoelastic anisotropy related to distribution of internal stresses and the shape anisotropy $[40,41,73,74]$. The increase in remanent magnetization, $M_{r} / M_{0}$, upon annealing (see Figure 8a) must be therefore attributed to the inner axially magnetized core, $R_{c}$, increase considering the link between $R_{c}$ and $M_{r} / M_{o}$ as $[40,74]$ :

$$
R_{c}=R\left(M_{r} / M_{o}\right)^{1 / 2}
$$

where $R$ is the metallic nucleus radius.

However, the modification in $\lambda_{s}$ upon annealing of amorphous materials with vanishing $\lambda_{s}$ can be a relevant factor [101]. Thus, an increase in $\lambda_{s}$ upon annealing of Co-rich microwires is reported elsewhere [102]. This influence of annealing on $\lambda_{s}$ value and even sign is explained by the stress, $\sigma$, (either applied or internal) dependence of $\lambda_{s}$, described as [101,102]:

$$
\lambda_{s, \sigma}=\lambda_{s, 0}-B \sigma
$$

where $\lambda_{s, \sigma}$ is the magnetostriction coefficient under stress, $\lambda_{s, 0}$ is the zero-stress magnetostriction coefficient, and $B$ is a positive coefficient of order $10^{-10} \mathrm{MPa}$. 


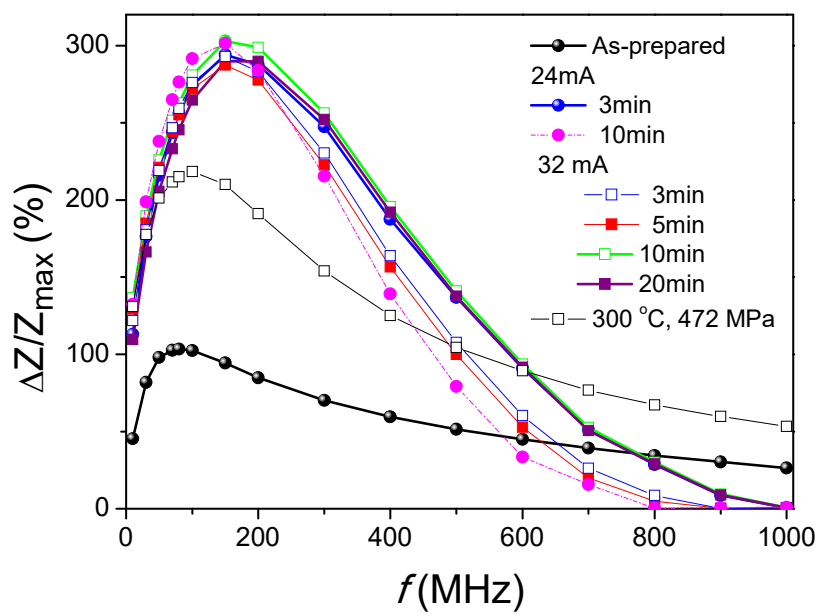

Figure 14. $\Delta \mathrm{Z} / \mathrm{Z}_{\max }(f)$ dependences observed in as-prepared and Joule heated at different annealing conditions and stress-annealed $\left(T_{a n n}=300{ }^{\circ} \mathrm{C}, \sigma_{m}=472 \mathrm{MPa}\right)$ samples. Adapted from [93].

The other source of magnetic hardening observed in Co-rich amorphous microwires is discussed in terms of the DW stabilization $[75,98,99]$. The origin of such DWs stabilization is associated with the diffusion of interstitial atoms or directional atomic ordering in ferromagnetic alloys consisting of at least two magnetic elements in the positions occupied by the DWs during annealing $[98,99]$. The DWs stabilization can be usually suppressed by magnetic field/stress-annealing $[98,99]$.

Consequently, we can assume that stress-annealing and Joule heating are promising methods for optimization of both magnetic softness and GMI effect of Co-rich microwires.

\subsection{Engineering of Magnetic Softness and GMI Effect in Amorphous Microwires with Positive Magnetostriction}

There are several advantages of Fe-rich microwires, such as higher saturation magnetization values and lower price of $\mathrm{Fe}$, which make them potentially attractive for GMI applications. However, as-prepared microwires with positive $\lambda_{s}$, characterized by rectangular hysteresis loops (see Figure $4 a-c$ ), usually have poor GMI performance (see example in Figure $7 \mathrm{~b}$ ). Therefore, a search for appropriate post-processing that allows for magnetic softening and GMI effect improvement is essentially relevant for applications of microwires with positive $\lambda_{s}$.

However, the character of the hysteresis loops of Fe-rich microwires annealed in a conventional furnace remains unchanged; a slight decrease in coercivity is observed for different $T_{a n n}$, while all hysteresis loops maintain a perfectly rectangular shape (see Figure 15a).
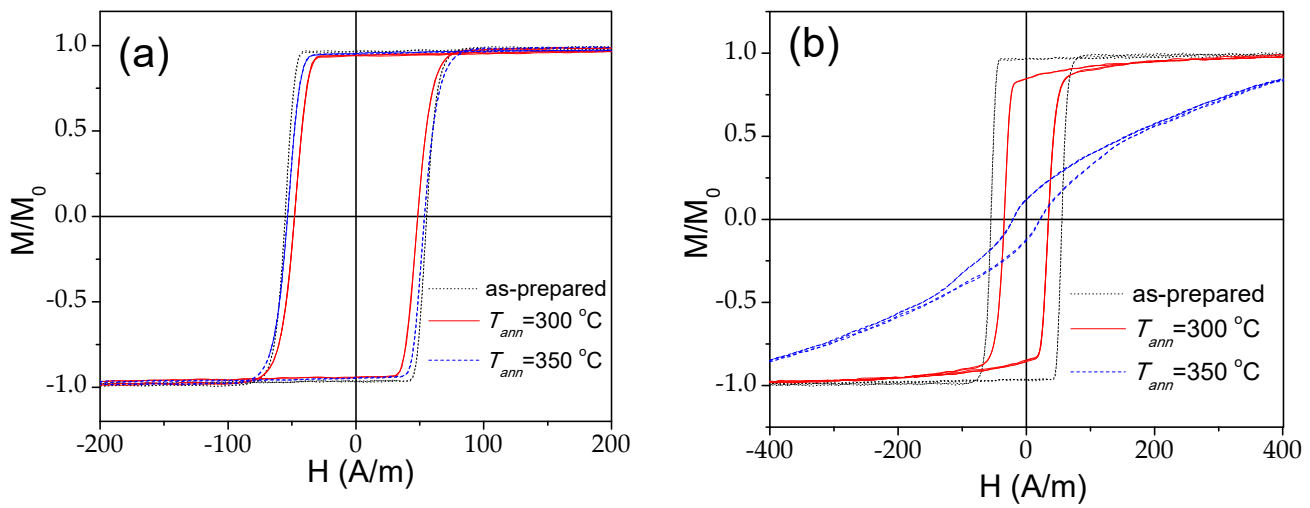

Figure 15. Hysteresis loops of as-prepared and annealed for $t_{a n n}=60 \mathrm{~min}$ at different $T_{a n n}$ samples (a) 
and stress-annealed at $\sigma_{m}=190 \mathrm{MPa}$ for the same $t_{a n n}$ and $T_{a n n} \mathrm{Fe}_{75} \mathrm{~B}_{9} \mathrm{Si}_{12} \mathrm{C}_{4}$ samples $(\mathbf{b})$. Reproduced with permission from [103].

Similarly, as-prepared and annealed Fe-Ni based microwires maintain rectangular character of hysteresis loops and hence relatively low $\Delta Z / Z_{\max }$ values (as compared to Co-rich microwires with vanishing $\lambda_{S}$ ) [104].

Similar to Co-rich microwires, transverse magnetic anisotropy can be induced by stressannealing of Fe-rich microwires [32,71,103,105]. Indeed, a gradual change in hysteresis loops from rectangular to linear is observed in the $\mathrm{Fe}_{75} \mathrm{~B}_{9} \mathrm{Si}_{12} \mathrm{C}_{4}$ microwire stress- annealed at the same annealing conditions $\left(t_{\text {ann }}\right.$ and $\left.T_{\text {ann }}\right)$ (see Figure $\left.15 b\right)$.

There are common features of stress-annealing induced magnetic anisotropy of Co- and Fe-rich microwires; in both cases induced anisotropy depends on $T_{a n n}, \sigma_{m}$ and $t_{a n n}$. Thus, there is a similar tendency: a decrease in remnant magnetization, $M_{r} / M_{0}$, and coercivity, and increase in magnetic anisotropy field, which are observed after stress-annealing at fixed $\sigma_{m}$ increasing $T_{a n n}$ (see Figure 15) or at fixed $T_{a n n}$ increasing $t_{a n n}$ or $\sigma_{m}$ (see Figures 16 and 17).
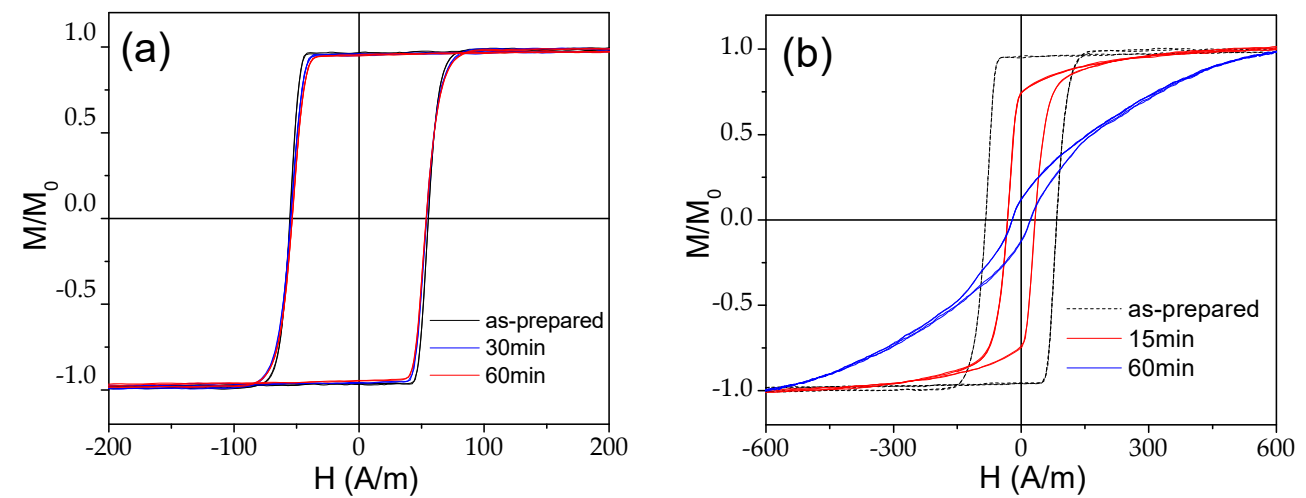

Figure 16. Hysteresis loops of as-prepared and annealed (a) and stress-annealed for $\sigma_{m}=190 \mathrm{MPa}$ (b) at $T_{\text {ann }}=350{ }^{\circ} \mathrm{C} \mathrm{Fe}_{75} \mathrm{~B}_{9} \mathrm{Si}_{12} \mathrm{C}_{4}$ microwires with $t_{\text {ann }}$ as a parameter. Reproduced with permission from [103].

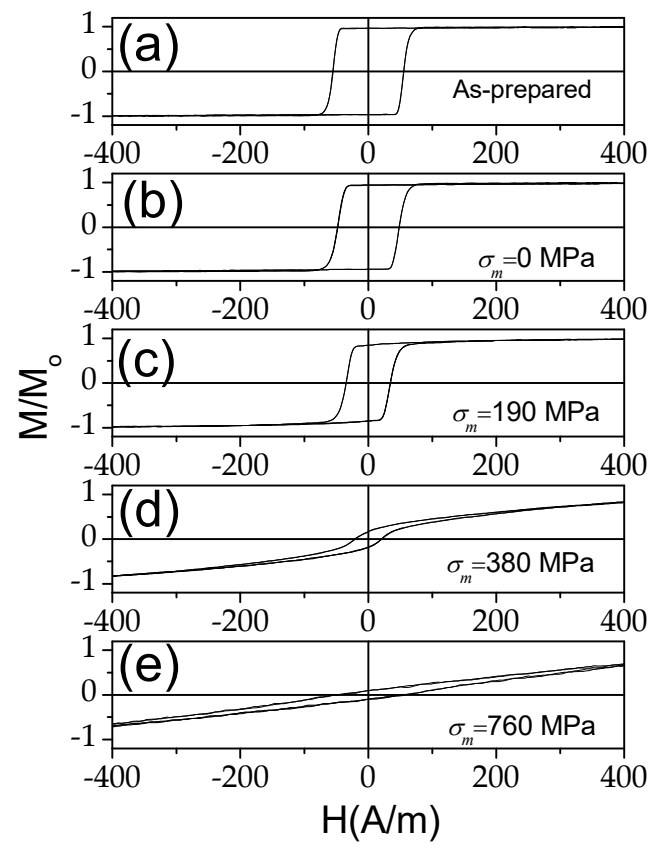

Figure 17. Hysteresis loops of as-prepared $\mathrm{Fe}_{75} \mathrm{~B}_{9} \mathrm{Si}_{12} \mathrm{C}_{4}$ microwire (a) and effect of tensile stress applied during the annealing at $300{ }^{\circ} \mathrm{C}\left(t_{\text {ann }}=60 \mathrm{~min}\right)$ on hysteresis loops of $\mathrm{Fe}_{75} \mathrm{~B}_{9} \mathrm{Si}_{12} \mathrm{C}_{4}$ microwire (b-e). Reproduced with permission from [103]. 
Accordingly, $\mathrm{Fe}_{75} \mathrm{~B}_{9} \mathrm{Si}_{12} \mathrm{C}_{4}$ microwires stress-annealed at sufficiently high $T_{a n n}, \sigma_{m}$, or $t_{\text {ann }}$ present substantial transverse magnetic anisotropy (see Figures 16 and 17).

The observed magnetic softening upon stress-annealing enables considerable improvement of GMI effect performance in Fe-rich microwires [71,103,105]. A comparison of $\Delta Z / Z(H)$ dependencies of as-prepared and stress-annealed $\mathrm{Fe}_{75} \mathrm{~B}_{9} \mathrm{Si}_{12} \mathrm{C}_{4}$ microwires is shown in Figure 18. In addition to a noticeable $\Delta Z / Z_{\max }$ value improvement in stressannealed $\mathrm{Fe}_{75} \mathrm{~B}_{9} \mathrm{Si}_{12} \mathrm{C}_{4}$ microwires, the character of the $\Delta Z / Z(H)$ dependencies changes from single to double peak (see Figure 18a,b). Previously, double peak $\Delta Z / Z(H)$ dependencies were predicted for magnetic wires with circumferential character of magnetic anisotropy, while single peak $\Delta Z / Z(H)$ dependencies were for wires with axial magnetic anisotropy [106]. Therefore, modification of both $\Delta Z / Z_{\text {max }}$ values and $\Delta Z / Z(H)$ dependencies satisfactorily correlate with change in hysteresis loop character upon stress-annealing.
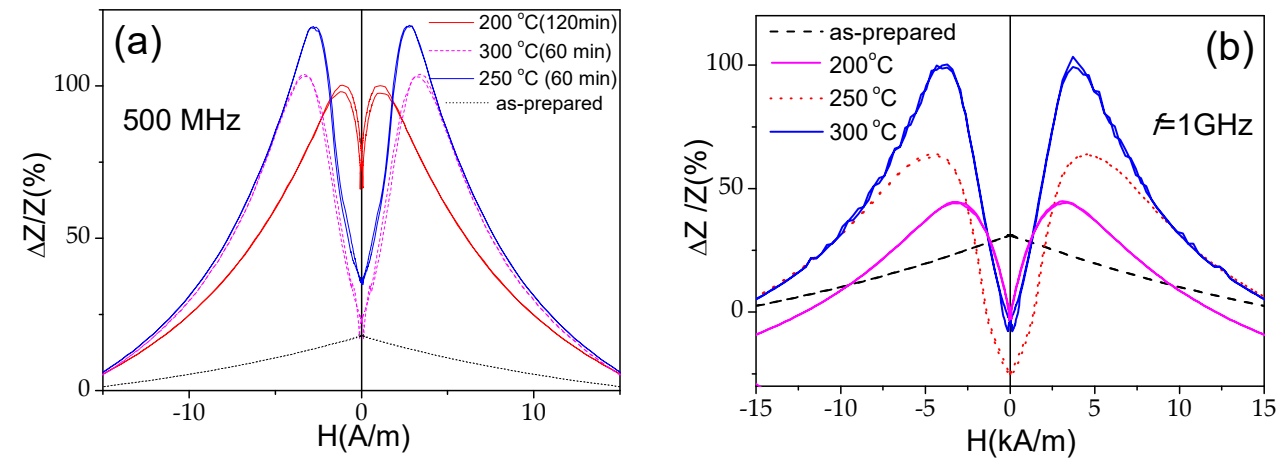

Figure 18. $\Delta \mathrm{Z} / \mathrm{Z}(H)$ dependencies measured in as-prepared and stress-annealed $\left(\sigma_{m} \approx 900 \mathrm{MPa}\right)$ at different $T_{\text {ann }}$ in $\mathrm{Fe}_{75} \mathrm{~B}_{9} \mathrm{Si}_{12} \mathrm{C}_{4}$ microwires measured at $500 \mathrm{MHz}(\mathbf{a})$ and $1 \mathrm{GHz}(\mathbf{b})$. Reproduced with permission from [71].

One of the peculiarities of $\Delta Z / Z(H)$ dependencies of stress-annealed Fe-rich microwires is unusual and irregular $\Delta Z / Z(H)$ dependencies at intermediate frequencies, $f$, range (roughly between 50 and $400 \mathrm{MHz}$ ) (see Figure 19b). At low frequencies (10-50 MHz), $\Delta \mathrm{Z} / \mathrm{Z}(\mathrm{H})$ dependencies present single peak character similarly to as-prepared $\mathrm{Fe}_{75} \mathrm{~B}_{9} \mathrm{Si}_{12} \mathrm{C}_{4}$ microwire (with a single maximum at $H=0$ ). For $f \geq 500 \mathrm{MHz} \Delta Z / Z(H)$ dependencies transform to double peak typical for wires with transverse magnetic anisotropy (see Figure 19c). The irregular $\Delta Z / Z(H)$ dependencies have been explained by the contribution of the inner axially magnetized core superposition with single peak $\Delta Z / Z(H)$ dependence and the double peak $\Delta Z / Z(H)$ dependence from the outer shell [103]. Indeed, from the $\delta(f)$ dependence given by Equation (1), one can predict a decrease in $\delta$ with increasing $f$. Therefore, the inner axially magnetized core contribution must decrease with increasing frequency.

These irregular $\Delta Z / Z(H)$ dependencies have been suppressed by the subsequent conventional furnace annealing followed by stress-annealing (see Figure 20a,b) [107]. Additionally, subsequent conventional furnace annealing followed by stress-annealing allowed for further improvement of $\Delta Z / Z_{\max }$ magnitude; values up to $160 \%$ have been achieved (see Figure 20a,b). 

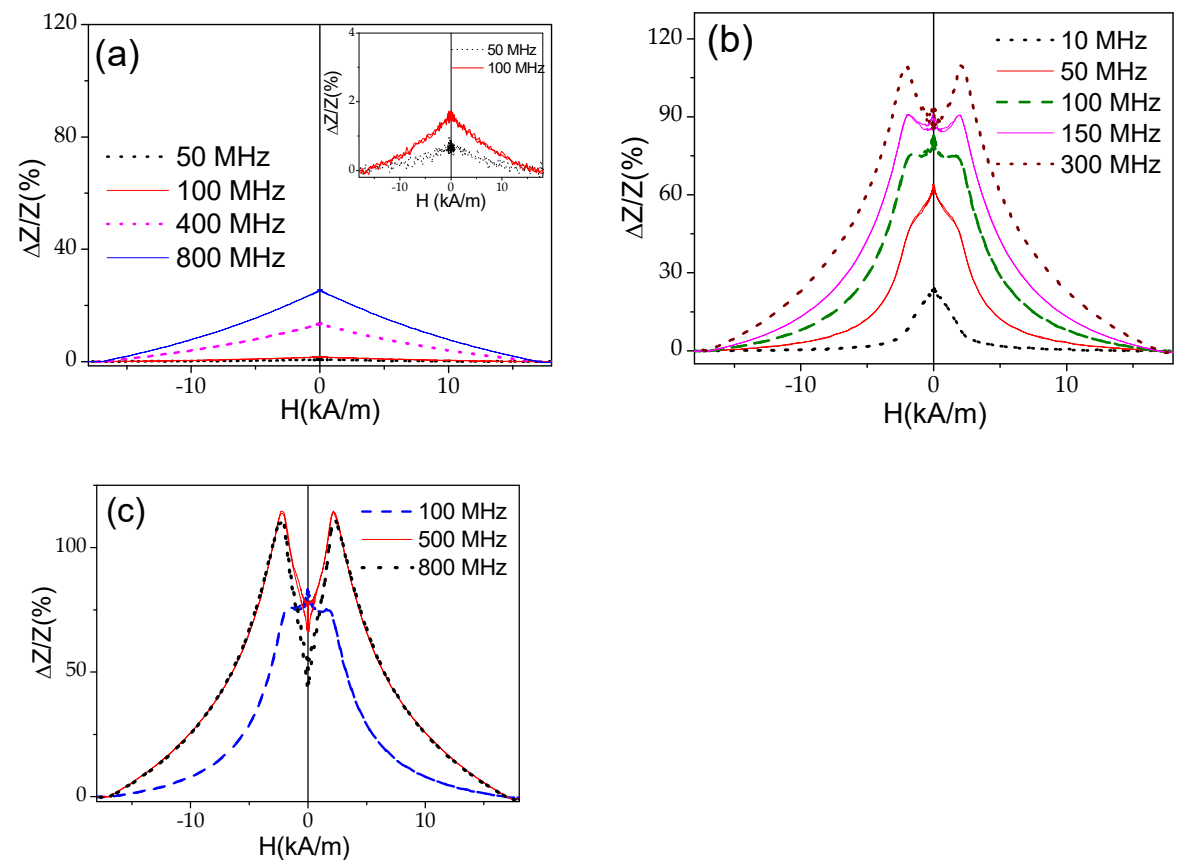

Figure 19. $\Delta \mathrm{Z} / \mathrm{Z}(H)$ dependencies observed in as-prepared (a) and stress-annealed at $T_{\text {ann }}=350{ }^{\circ} \mathrm{C}$ (for $60 \mathrm{~min}$ and $\sigma_{m}=190 \mathrm{MPa}$ ) $\mathrm{Fe}_{75} \mathrm{~B}_{9} \mathrm{Si}_{12} \mathrm{C}_{4}$ microwires measured at $10 \leq f \leq 300 \mathrm{MHz}(\mathbf{b}$ ) and at $f \geq 500 \mathrm{MHz}$ (c). Adapted from [103].
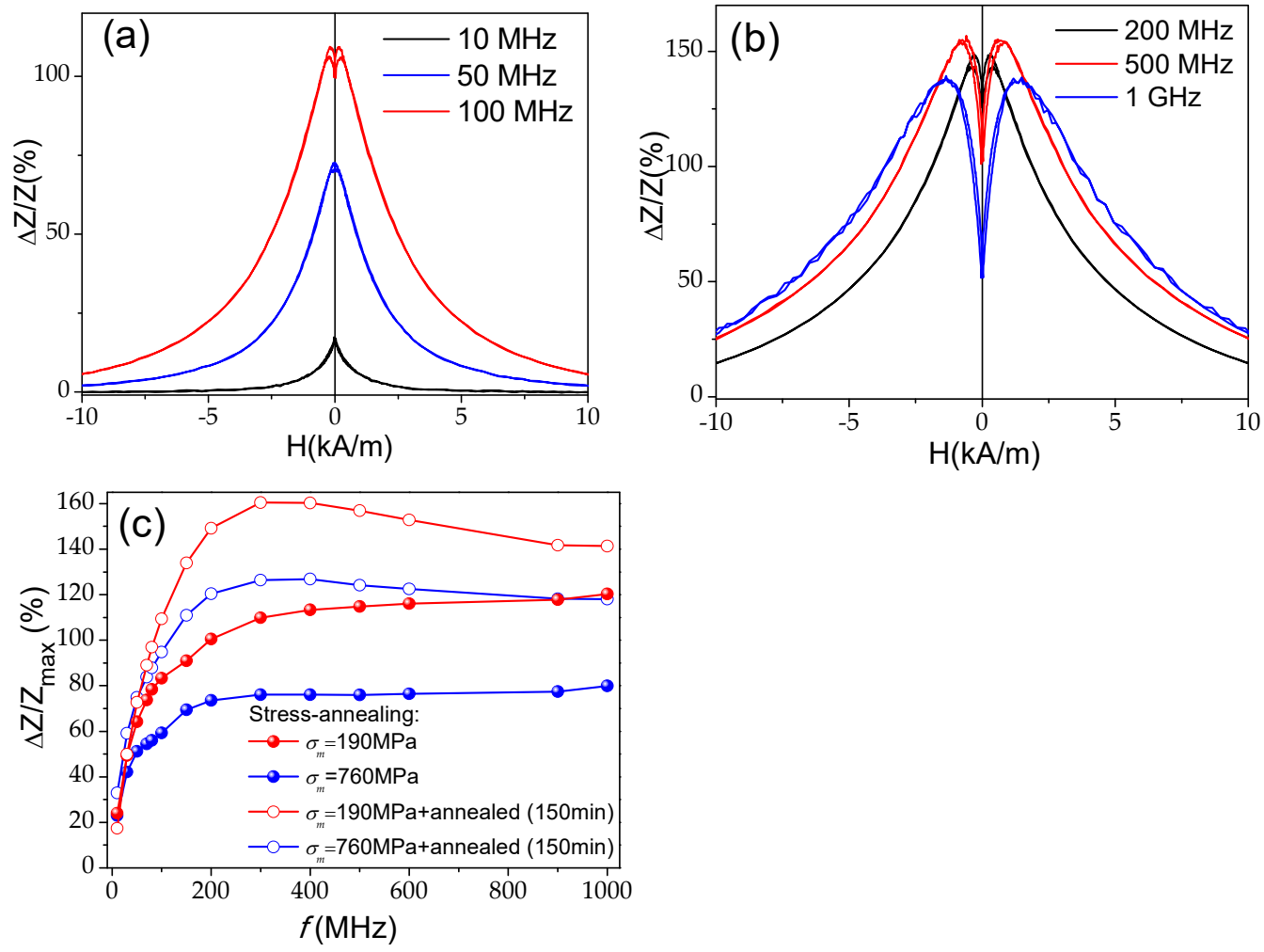

Figure 20. $\Delta \mathrm{Z} / \mathrm{Z}(H)$ dependences of stress-annealed $\left(T_{a n n}=350{ }^{\circ} \mathrm{C}, \sigma_{m}=190 \mathrm{MPa}\right)$ and subsequently annealed $\mathrm{Fe}_{75} \mathrm{~B}_{9} \mathrm{Si}_{12} \mathrm{C}_{4}$ microwires measured at $f \leq 100 \mathrm{MHz}$ (a) and at $f \geq 100 \mathrm{MHz}(\mathbf{b})$ and $\Delta Z / Z$ max $(f)$ dependencies of stress-annealed $\left(\sigma_{m}=190 \mathrm{MPa}\right.$ and $\left.760 \mathrm{MPa}\right)$ and subsequently annealed for 150 min $\mathrm{Fe}_{75} \mathrm{~B}_{9} \mathrm{Si}_{12} \mathrm{C}_{4}$ microwires (c). Plots $(\mathbf{a}, \mathbf{b})$ are reprinted with permission from [107], and plot (c) is adapted from [107]. 
Recently, the influence of Joule heating on the magnetic properties and the GMI effect of the $\mathrm{Fe}_{75} \mathrm{~B}_{9} \mathrm{Si}_{12} \mathrm{C}_{4}$ microwire has been evaluated [108,109]. As in the case of Co-rich microwires, an improvement of $\Delta Z / Z_{\text {max }}$ by almost an order of magnitude is observed in Joule heated $\left(j \approx 110 \mathrm{~A} / \mathrm{mm}^{2}\right.$ ) $\mathrm{Fe}_{75} \mathrm{~B}_{9} \mathrm{Si}_{12} \mathrm{C}_{4}$ microwires (see Figure 21a). However, the hysteresis loop character of the Joule annealed $\mathrm{Fe}_{75} \mathrm{~B}_{9} \mathrm{Si}_{12} \mathrm{C}_{42}$ microwire remains quite similar to the as-prepared sample (see Figure 21b).

Additionally, after Joule heating of the $\mathrm{Fe}_{75} \mathrm{~B}_{9} \mathrm{Si}_{12} \mathrm{C}_{42}$ microwire, the $\Delta Z / Z(H)$ dependencies change from a single peak to a double peak (see Figure 21a). This evolution of $\Delta \mathrm{Z} / \mathrm{Z}(H)$ dependencies must be associated to low circumferential magnetic anisotropy induced by Joule heating.

As discussed above, the origin of stress-induced anisotropy in amorphous materials is still unclear and commonly discussed considering "back stresses", the atomic directional pair ordering or topological short range ordering [86-89,110]. In the present case, stressannealing induced anisotropy is observed in both types of microwires: Fe-rich with only one ferromagnetic element (Fe) and Co-rich microwires containing $\mathrm{Fe}$ and $\mathrm{Ni}$.

The contributions of atomic directional pair ordering and back stresses cannot be completely excluded. However, the irreversible character of the stress-annealing induced magnetic anisotropy obtained upon stress-annealing at elevated $\sigma_{m}$ indicates a relevant contribution from topological short-range ordering (also known as structural anisotropy) [107].
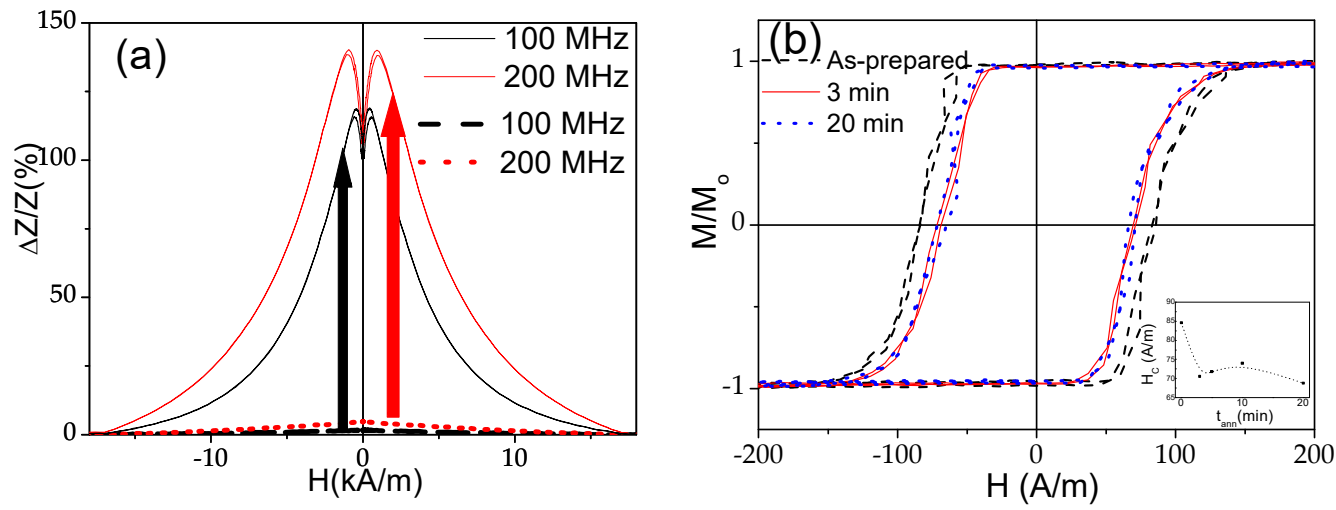

Figure 21. $\Delta \mathrm{Z} / \mathrm{Z}(\mathrm{H})$ dependences of as-prepared and Joule heated $\left(j \approx 110 \mathrm{~A} / \mathrm{mm}^{2}\right)$ for $3 \mathrm{~min}$ (a) measured at $f=100$ and $200 \mathrm{MHz}$ and hysteresis loops of as-prepared and Joule heated $\mathrm{Fe}_{75} \mathrm{~B}_{9} \mathrm{Si}_{12} \mathrm{C}_{4}$ microwires (b).

The yield stress of most amorphous materials at room temperature is of the order of $700 \mathrm{MPa}$. Therefore, a certain amount of creep and plastic deformation could occur for stress-annealed microwires, giving rise to irreversible stress-annealing induced anisotropy. On the other hand, the yield stress value is affected by the diameter and by the chemical composition $[13,111]$. Thus, the yield stress of glass-coated Fe-B microwires with diameter of the order of 10-20 $\mu \mathrm{m}$ can be substantially increased by additions of Co and Si up to 4.4 GPa [111].

The dependence of stress-annealing induced anisotropy on the stress-annealing conditions was recently employed to develop magnetic microwires with graded magnetic anisotropy [105,112]. Fe-rich microwires with a graded magnetic anisotropy were prepared by stress-annealing at a variable annealing temperature. In magnetic materials with graded magnetic anisotropy, a controllable spatial distribution of magnetic anisotropy can be obtained.

Controlled DW injection or trapping, previously predicted for thin films with graded magnetic anisotropy [113], were experimentally demonstrated in such magnetic microwires with graded magnetic anisotropy [105,112]. Earlier, to obtain the graded magnetic anisotropy in thin films, a rather complex method was used, consisting in the modification of the chemical composition during the thin film preparation $[114,115]$. 
As mentioned, reported elsewhere [3,4,10-15], amorphous magnetic materials can present not only excellent soft magnetic properties, but also high mechanical and anticorrosive properties. Although the nanocrystallization allows for considerable magnetic softening of certain amorphous alloys (for example, Finemet-type alloys) [3,10,56], the devitrification also involved drastic deterioration of mechanical properties [14]. In this review, we focused on only completely amorphous microwires coated by amorphous glass (which also prevents corrosion). Accordingly, all microwires studied were completely amorphous. The amorphous origin of structure was confirmed several times by different structural methods (X-ray diffraction, DSC) [82,83]. All annealing conditions $\left(T_{a n n}, t_{\text {ann }}\right)$ were selected in order to avoid the crystallization typically observed in the microwires studied at $T_{\text {ann }} \approx 500{ }^{\circ} \mathrm{C}[83]$.

The main pinning mechanisms of amorphous materials have been identified and discussed by Kronmüller et al. [116-118]. In amorphous materials, the domain structure is mostly determined by three different types of anisotropy energies: shape anisotropy (including the surface irregularities), magnetoelastic anisotropy, and structure anisotropy [116-118].

Accordingly, the existence of the interfacial layer (see Figure 2a-g) and the fluctuations of the internal stresses related to the presence of bubbles spontaneously distributed in the glass coating can affect the DW pinning.

The remarkable effect observed of stress-annealing induced magnetic anisotropy must be attributed to the contribution from structural anisotropy. This structure anisotropy in asprepared amorphous materials is usually attributed to temperature gradients or magnetic fields occurring during the fabrication process. The possible origins are either gradients in the distribution of metalloid atoms, short range atomic pair ordering in amorphous materials containing two or more ferromagnetic elements, or the angular distribution of atomic bonds and small anisotropic structural rearrangements at the temperature near glass transition $[87,118]$. The evidence of such structural anisotropy in amorphous materials has been confirmed by energy dispersive X-ray diffraction (EDXD) [87].

Recently, we observed that such stress-annealing induced anisotropy in Fe-rich microwires can be annealed out only partially [107]. Therefore, the magnetic anisotropy related to back stresses can be responsible for the reversible stress-annealing induced anisotropy [107].

In certain cases, such as thicker magnetic wires prepared by melt extraction, strong stresses produced by cold-drawn can produce the mechanical deformation that induces the precipitation of nanocrystals [119]. However, this was not the case for studied as-prepared and annealed glass-coated amorphous microwires.

On the other hand, the origin of the GMI effect is commonly attributed to the magnetic field dependence of skin depth, $\delta$, of magnetically soft conductor and explained in terms of classical electrodynamics [16,28-31]. The GMI effect features are linked to magnetic properties of the surface layer. In several publications, $\delta(H)$ dependencies were evaluated and showed that the minimum skin depth values, $\delta_{\text {min }}$, at $f \geq 100 \mathrm{MHz}$ are of about $1-2 \mu \mathrm{m}$, reaching values of $\delta_{\text {min }} \approx 1.2 \mu \mathrm{m}$ at $1 \mathrm{GHz}$ [68]. These $\delta_{\min }$ values are comparable to the thickness of the interfacial layer (about $0.5 \mu \mathrm{m}$ ) (see Figure 2). Accordingly, we can assume that the spatial distribution of magnetic anisotropy in the surface layer of metallic nucleus can be affected by the interfacial layer.

Evolution of the $\Delta Z / Z /(H)$ dependencies and $\Delta Z / Z \max$ for $\mathrm{Fe}_{75} \mathrm{~B}_{9} \mathrm{Si}_{12} \mathrm{C}_{4}$ and $\mathrm{Co}_{67} \mathrm{Fe}_{3.9}$ $\mathrm{Ni}_{1.4} \mathrm{~B}_{11.5} \mathrm{Si}_{14.5} \mathrm{Mo}_{1.6}$ microwires subjected to various heat treatments (annealing, stressannealing, and Joule heating) at selected frequencies, $f,(10,100,200$, and $500 \mathrm{MHz})$ is shown in Figure 22. Intermediate frequencies are selected considering that the highest $\Delta \mathrm{Z} / \mathrm{Zmax}$ values are usually observed at $f \approx 100-200 \mathrm{MHz}$.

Generally, the link between magnetic anisotropy and $\Delta Z / Z /(H)$ dependencies and $\Delta Z / Z \max$ can be clearly identified in most of the microwires studied. Thus, a decay in $\Delta \mathrm{Z} / \mathrm{Z}(H)$ from $\mathrm{H}=0$ for all $f$-values and rather low $\Delta \mathrm{Z} / \mathrm{Zmax}$ value are observed for asprepared $\mathrm{Fe}_{75} \mathrm{~B}_{9} \mathrm{Si}_{12} \mathrm{C}_{4}$ microwires with rectangular hysteresis loop (see Figure 22a). These 
single peak $\Delta Z / Z(H)$ dependencies are predicted and observed experimentally for magnetic wires with axial magnetic anisotropy [28-31,106].

However, almost an order of magnitude higher $\Delta \mathrm{Z} / \mathrm{Z} \max$ value and double peak $\Delta \mathrm{Z} / \mathrm{Z}(H)$ dependencies are observed in as-prepared $\mathrm{Co}_{67} \mathrm{Fe}_{3.9} \mathrm{Ni}_{1.4} \mathrm{~B}_{11.5} \mathrm{Si}_{14.5} \mathrm{Mo}_{1.6}$ microwires (Figure 22e), and in stress-annealed $\mathrm{Fe}_{75} \mathrm{~B}_{9} \mathrm{Si}_{12} \mathrm{C}_{4}$ microwires with transverse induced magnetic anisotropy (Figure 22b). These double peak $\Delta Z / Z(H)$ dependencies are typical for magnetic wires with transverse magnetic anisotropy $[28-31,106]$.

The $\Delta \mathrm{Z} / \mathrm{Z}(\mathrm{H})$ dependencies shown in Figure $22 \mathrm{~b}$ were obtained for $\mathrm{Fe}_{75} \mathrm{~B}_{9} \mathrm{Si}_{12} \mathrm{C}_{4}$ microwires stress-annealed at $\sigma_{m}=760 \mathrm{MPA}$, with a rather strong induced transverse magnetic anisotropy. Therefore, the $\Delta \mathrm{Z} / \mathrm{Z}$ max values observed in these $\mathrm{Fe}_{75} \mathrm{~B}_{9} \mathrm{Si}_{12} \mathrm{C}_{4}$ microwires are lower than those observed for the same microwires stress-annealed at $\sigma_{m}=190 \mathrm{MPa}$ (see Figure 19). The irregularity in the $\Delta Z / Z(H)$ dependencies at intermediate frequencies ( $f=100$ and $200 \mathrm{MHz}$ ), observed in both stress-annealed microwires, was attributed to the superposition of the contributions coming from the inner axially magnetized core (having a single peak $\Delta Z / Z(H)$ dependence) and a double peak $\Delta Z / Z(H)$ dependence from the outer shell with transverse magnetic anisotropy. This irregularity in the $\Delta Z / Z(H)$ dependencies can be suppressed by subsequent annealing (see Figure 22c), which also allows for the reduction of strong transverse induced magnetic anisotropy due to partial relaxation of the reversible part of the stress-annealing induced anisotropy. In this case, the double peak $\Delta \mathrm{Z} / \mathrm{Z}(H)$ dependence is observed at $f \geq 100 \mathrm{MHz}$ (see Figure 22) and higher $\Delta \mathrm{Z} / \mathrm{Zmax}$ values are observed. Joule heating is an alternative route for $\Delta \mathrm{Z} / \mathrm{Z}$ max improvement in Feand Co-rich microwires (see Figure 22d,g). However, the hysteresis loops of Joule heated microwires are rather similar to those of as-prepared microwires. Therefore, the GMI ratio improvement in Joule heated microwires can be attributed to heating in the presence of the Oersted magnetic field during Joule heating.

The magnetic softness and GMI effect of Co-rich microwires stress-annealed at appropriate annealing conditions $\left(T_{a n n}, t_{a n n}\right.$ or $\sigma_{m}$ ) can be substantially improved (see Figure 22f). The double peak $\Delta Z / Z(H)$ dependence is observed over the entire $f$ range, while the maxima in the $\Delta Z / Z(H)$ dependencies are observed at a lower magnetic field, $H_{m}$.

Despite the rectangular hysteresis loop of the annealed Co-rich microwire, the double peak $\Delta Z / Z(H)$ dependence observed at $f \geq 200 \mathrm{MHz}$ in this microwire is attributed to the circumferential magnetization alignment of the outer domain shell [44].

In general, higher $\Delta Z / Z_{\max }$ values are observed in properly processed Co-rich microwires. However, higher $\Delta Z / Z_{\max }$ are observed at elevated (e.g., $f=500 \mathrm{MHz}$ ) frequencies in stress-annealed or Joule heated Fe-rich microwires.

Although magnetic softness is one of the prerequisites for GMI effect optimization, the domain walls become strongly damped by eddy currents at frequencies above $10 \mathrm{MHz}$ [120]. All of the results provided consider frequencies above $10 \mathrm{MHz}$ (most are above $100 \mathrm{MHz}$ ). Consequently, the GMI effect at elevated frequencies is discussed in terms of the fundamental link between ferromagnetic resonance, FMR, and GMI [69,120-122]. However, the AC Oersted field distribution is influenced by the skin effect, and therefore it is necessary to consider the FMR for the heterogeneous driving field [122].

Aforementioned results on effect of stress-annealing and Joule heating on magnetic properties and GMI effect provide efficient routes to enhance magnetic softness and GMI effect in magnetic microwires. A remarkable GMI effect improvement can be achieved by appropriate post-processing. 

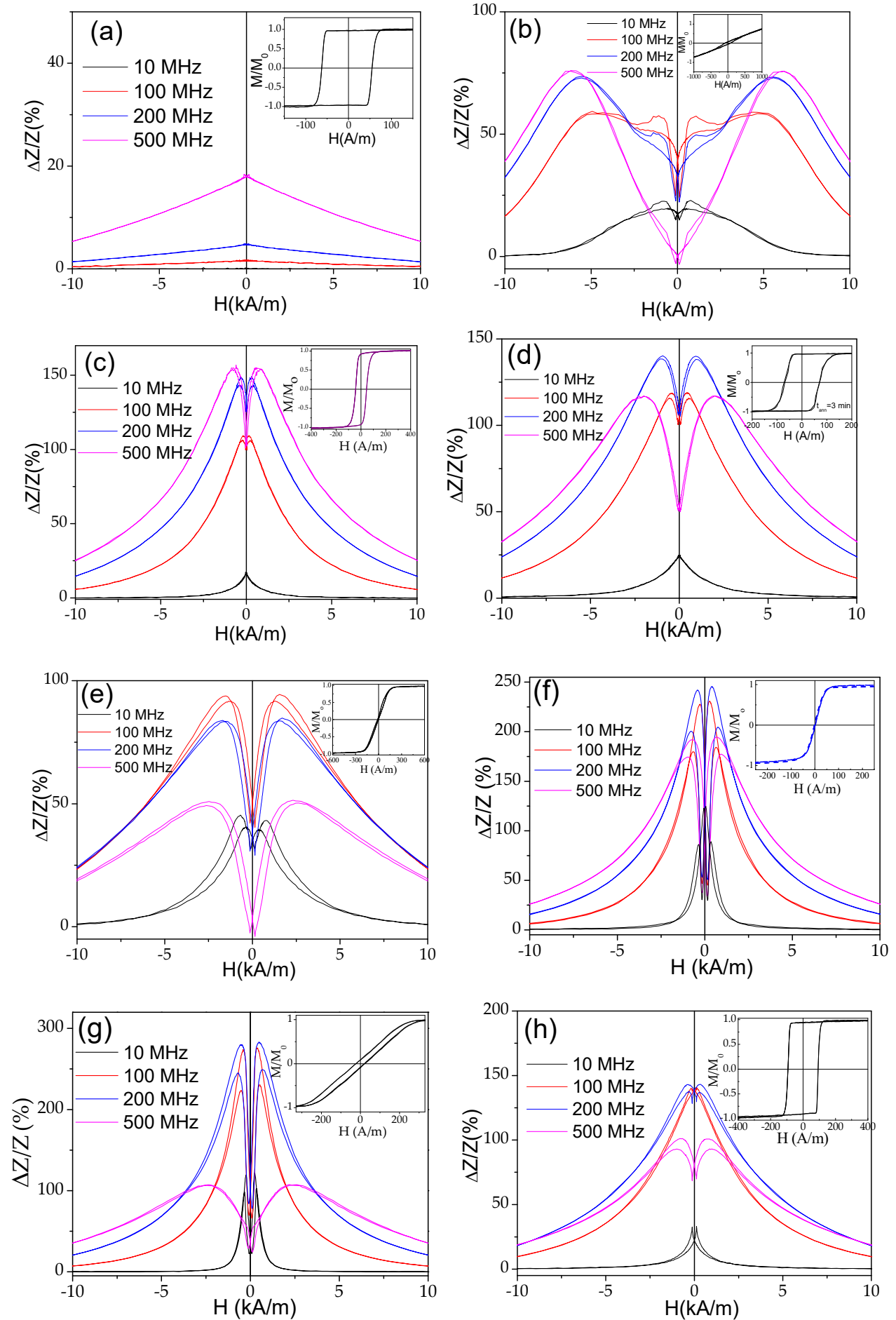

Figure 22. $\Delta \mathrm{Z} / \mathrm{Z}(\mathrm{H})$ dependences of as-prepared (a), stress-annealed $\left(\mathrm{T}_{\text {ann }}=350{ }^{\circ} \mathrm{C}, 760 \mathrm{MPa}\right)$ $(\mathbf{b})$, stress-annealed $\left(T_{a n n}=350{ }^{\circ} \mathrm{C}, 760 \mathrm{MPa}\right)\left(+\right.$ annealed $\left(T_{a n n}=350{ }^{\circ} \mathrm{C}\right)(\mathbf{c})$, and Joule heated $\left(j \approx 110 \mathrm{~A} / \mathrm{mm}^{2}\right.$ for $3 \mathrm{~min}$ ) (d) $\mathrm{Fe}_{75} \mathrm{~B}_{9} \mathrm{Si}_{12} \mathrm{C}_{4}$ microwires and as-prepared (e), stress-annealed $\left(350{ }^{\circ} \mathrm{C}, 472 \mathrm{MPa}\right)(\mathbf{f})$, Joule heated $\left(j \approx 110 \mathrm{~A} / \mathrm{mm}^{2}\right.$ for $\left.3 \mathrm{~min}\right)(\mathrm{g})$, and annealed at $300{ }^{\circ} \mathrm{C}$ (h) $\mathrm{Co}_{67} \mathrm{Fe}_{3.9} \mathrm{Ni}_{1.4} \mathrm{~B}_{11.5} \mathrm{Si}_{14.5} \mathrm{Mo}_{1.6}$ microwire measured at $f=10,100,200$, and $500 \mathrm{MHz}$. The hysteresis loops are provided in the insets.

\section{Conclusions}

We summarized the magnetic properties and GMI performance of amorphous magnetic glass-coated microwires and the methods that allow for improving magnetic softness and GMI effect. Glass-coated magnetic microwires with amorphous structure present a 
unique combination of soft magnetic properties together with thin dimensions and excellent mechanical and anticorrosive properties. Tunable magnetic properties together with new functionalities provided by an insulating, flexible, and biocompatible glass coating make these microwires suitable for various technological applications, including magnetic and magnetoelastic sensors.

Several routes for optimization of the magnetic properties of magnetic microwires are provided. Magnetic softness and GMI effect of microwires with a vanishing magnetostriction coefficient can be substantially improved by appropriate annealing (including stress-annealing and Joule heating). As-prepared amorphous microwires with positive magnetostriction coefficient and rectangular hysteresis loops are unsuitable for GMI applications. However, magnetic softness and GMI effect have been remarkably improved through appropriate post-processing, including stress-annealing, Joule heating, and combined stress-annealing, followed by conventional furnace annealing, which can significantly improve the GMI effect (by more than an order of magnitude).

Author Contributions: Conceptualization, A.Z. and V.Z.; methodology, M.I., J.M.B. and V.Z.; validation, A.Z.; formal analysis, A.Z. and V.Z.; investigation, A.Z., P.C.-L., L.G.-L., A.G. and V.Z.; resources, A.Z. and V.Z.; data curation, V.Z., P.C.-L., A.G., J.M.B., L.G.-L. and M.I., writing-original draft preparation, A.Z., P.C.-L. and V.Z.; writing-review and editing, A.Z., P.C.-L. and V.Z.; supervision, A.Z.; funding acquisition, A.Z. and V.Z. All authors have read and agreed to the published version of the manuscript.

Funding: This work was funded by Spanish MCIU under PGC2018-099530-B-C31 (MCIU/AEI/FEDER, UE), by EU under "INFINITE"(Horizon 2020) project, by the Government of the Basque Country, under PIBA 2018-44, PUE_2021_1_0009, and Elkartek (CEMAP and AVANSITE) projects, by the Diputación Foral de Gipuzkoa in the frame of Programa "Red guipuzcoana de Ciencia, Tecnología e Innovación 2021" under 2021-CIEN-000007-01 project and by the University of Basque Country, under the COLAB20/15 project.

Institutional Review Board Statement: Not applicable.

Informed Consent Statement: Not applicable.

Data Availability Statement: Data available on request due to restrictions related to the developing projects.

Acknowledgments: The authors are thankful for technical and human support provided by SGIker of UPV/EHU (Medidas Magnéticas Gipuzkoa) and European funding (ERDF and ESF).

Conflicts of Interest: The authors declare no conflict of interest.

\section{References}

1. Fiorillo, F.; Bertotti, G.; Appino, C.; Pasquale, M. Soft Magnetic Materials. In Wiley Encyclopedia of Electrical and Electronics Engineering; Webster, J., Ed.; John Wiley \& Sons, Inc.: Torino, Italy, 1999; p. 42. [CrossRef]

2. Lenz, J.; Edelstein, A.S. Magnetic sensors and their applications. IEEE Sens. J. 2006, 6, 631-649. [CrossRef]

3. Herzer, G. Magnetic materials for electronic article surveillance. J. Magn. Magn. Mater. 2003, 254-255, 598-602. [CrossRef]

4. Zhukov, A.; Ipatov, M.; Corte-Leon, P.; Blanco, J.M.; Zhukova, V. Advanced functional magnetic microwires for magnetic sensors suitable for biomedical applications. In Magnetic Materials and Technologies for Medical Applications; Tishin, A.M., Ed.; Elsevier: Amsterdam, The Netherlands, 2022; Ch. 18. [CrossRef]

5. Ripka, P.; Vertesy, G. Sensors based on soft magnetic materials Panel discussion. J. Magn. Magn. Mater. 2000, 215, 795-799. [CrossRef]

6. Morón, C.; Cabrera, C.; Morón, A.; García, A.; González, M. Magnetic Sensors Based on Amorphous Ferromagnetic Materials: A Review. Sensors 2015, 15, 28340-28366. [CrossRef] [PubMed]

7. Díaz-Michelena, M. Small Magnetic Sensors for Space Applications. Sensors 2009, 9, 2271-2288. [CrossRef] [PubMed]

8. Baibich, M.N.; Broto, J.M.; Fert, A.; Nguyen Van Dau, F.; Petron, F.; Etienne, P.; Creuzer, G.; Friederich, A.; Chazelas, J. Giant Magnetoresistance of (001)Fe/(001)Cr Magnetic Superlattices. Phys. Rev. Lett. 1988, 61, 2472. [CrossRef] [PubMed]

9. Inoue, J.; Maekawa, S. Theory of tunneling magnetoresistance in granular magnetic films. Phys. Rev. B 1996, 53, R11927. [CrossRef]

10. Hasegawa, R. Applications of Amorphous Magnetic Alloys. In Properties and Applications of Nanocrystalline Alloys from Amorphous Precursors; Idzikowski, B., Švec, P., Miglierini, M., Eds.; NATO Science Series (Series II: Mathematics, Physics and Chemistry); Springer: Dordrecht, The Netherlands, 2005; Volume 184, pp. 189-198. 
11. Schuh, C.A.; Hufnagel, T.C.; Ramamurty, U. Mechanical behavior of amorphous alloys. Acta Mater. 2007, 55, 4067-4109. [CrossRef]

12. Hagiwara, M.; Inoue, A.; Masumoto, T. Mechanical properties of Fe-Si-B amorphous wires produced by in-rotating-water spinning method. Metall. Trans. A 1982, 13, 373-382. [CrossRef]

13. Goto, T.; Nagano, M.; Wehara, N. Mechanical properties of amorphous $\mathrm{Fe}_{80} \mathrm{P}_{16} \mathrm{C}_{3} \mathrm{~B}_{1}$ filament produced by glass-coated melt spinning. Trans. Jpn. Inst. Met. 1977, 18, 759-764. [CrossRef]

14. Zhukova, V.; Cobeño, A.F.; Zhukov, A.; de Arellano Lopez, A.R.; López-Pombero, S.; Blanco, J.M.; Larin, V.; Gonzalez, J. Correlation between magnetic and mechanical properties of devitrified glass-coated $\mathrm{Fe}_{71.8} \mathrm{Cu}_{1} \mathrm{Nb}_{3.1} \mathrm{Si}_{15} \mathrm{~B}_{9.1}$ microwires. J. Magn . Magn. Mater. 2002, 249, 79-84. [CrossRef]

15. Masumoto, T.; Hashimoto, K. Corrosion properties of amorphous metals. J. Phys. Colloq. 1980, 41, C8-894-C8-900. [CrossRef]

16. Mohri, K.; Uchiyama, T.; Panina, L.V.; Yamamoto, M.; Bushida, K. Recent Advances of Amorphous Wire CMOS IC MagnetoImpedance Sensors: Innovative High-Performance Micromagnetic Sensor Chip. J. Sens. 2015, 2015, 718069. [CrossRef]

17. Zhukova, V.; Corte-Leon, P.; Blanco, J.M.; Ipatov, M.; Gonzalez, J.; Zhukov, A. Electronic Surveillance and Security Applications of Magnetic Microwires. Chemosensors 2021, 9, 100. [CrossRef]

18. Honkura, Y.; Honkura, S. The Development of ASIC Type GSR Sensor Driven by GHz Pulse Current. Sensors 2020, 20 , 1023. [CrossRef]

19. Sabol, R.; Klein, P.; Ryba, T.; Hvizdos, L.; Varga, R.; Rovnak, M.; Sulla, I.; Mudronova, D.; Galik, J.; Polacek, I.; et al. Novel Applications of Bistable Magnetic Microwires. Acta Phys. Pol. A 2017, 131, 1150-1152. [CrossRef]

20. Makhnovskiy, D.; Fry, N.; Zhukov, A. On different tag reader architectures for bistable microwires. Sens. Actuat. A Phys. 2011, 166, 133-140. [CrossRef]

21. Von Gutfeld, R.J.; Dicello, J.F.; McAllister, S.J.; Ziegler, J.F. Amorphous magnetic wires for medical locator applications. Appl. Phys. Lett. 2002, 81, 1913-1915. [CrossRef]

22. Kozejova, D.; Fecova, L.; Klein, P.; Sabol, R.; Hudak, R.; Sulla, I.; Mudronova, D.; Galik, J.; Varga, R. Biomedical applications of glass-coated microwires. J. Magn. Magn. Mater. 2019, 470, 2-5. [CrossRef]

23. Zhukov, A.; Cobeño, A.F.; Gonzalez, J.; Blanco, J.M.; Aragoneses, P.; Dominguez, L. Magnetoelastic sensor of level of the liquid based on magnetoelastic properties of Co-rich microwires. Sens. Actuat. A Phys. 2000, 81, 129-133. [CrossRef]

24. Praslička, D.; Blažek, J.; Šmelko, M.; Hudák, J.; Čverha, A.; Mikita, I.; Varga, R.; Zhukov, A. Possibilities of Measuring Stress and Health Monitoring in Materials Using Contact-Less Sensor Based on Magnetic Microwires. IEEE Trans. Magn. 2013, 49, 128-131. [CrossRef]

25. Talaat, A.; Alonso, J.; Zhukova, V.; Garaio, E.; García, J.A.; Srikanth, H.; Phan, M.H.; Zhukov, A. Ferromagnetic glass-coated microwires with good heating properties for magnetic hyperthermia. Sci. Rep. 2016, 6, 39300. [CrossRef]

26. Mitxelena-Iribarren, O.; Campisi, J.; Martínez de Apellániz, I.; Lizarbe-Sancha, S.; Arana, S.; Zhukova, V.; Mujika, M.; Zhukov, A. Glass-coated ferromagnetic microwire-induced magnetic hyperthermia for in vitro cancer cell treatment. Mater. Sci. Eng. C 2020, 106, 110261. [CrossRef]

27. Qin, F.X.; Peng, H.X.; Phan, M.H.; Panina, L.V.; Ipatov, M.; Zhukov, A. Effects of wire properties on the field-tunable behaviour of continuous-microwire composites. Sens. Actuat. A Phys. 2012, 178, 118-125. [CrossRef]

28. Panina, L.V.; Mohri, K. Magneto-impedance effect in amorphous wires. Appl. Phys. Lett. 1994, 65, 1189-1191.

29. Beach, R.; Berkowitz, A. Giant magnetic field dependent impedance of amorphous FeCoSiB wire. Appl. Phys. Lett. 1994, 64, 3652-3654. [CrossRef]

30. Knobel, M.; Vazquez, M.; Kraus, L. Giant magnetoimpedance. In Handbook of Magnetic Materials; Bruck, E., Ed.; Elsevier: Amsterdam, The Netherlands, 2003; Volume 15, pp. 497-563.

31. Zhukov, A.; Ipatov, M.; Corte-León, P.; Gonzalez-Legarreta, L.; Churyukanova, M.; Blanco, J.M.; Gonzalez, J.; Taskaev, S.; Hernando, B.; Zhukova, V. Giant magnetoimpedance in rapidly quenched materials. J. Alloys Compd. 2020, 814, 152225. [CrossRef]

32. Zhukov, A.; Ipatov, M.; Corte-León, P.; Gonzalez-Legarreta, L.; Blanco, J.M.; Zhukova, V. Soft Magnetic Microwires for Sensor Applications. J. Magn. Magn. Mater. 2020, 498, 166180. [CrossRef]

33. Mohri, K.; Uchiyama, T.; Panina, L.V. Recent advances of micro magnetic sensors and sensing application. Sens. Actuat. A Phys. 1997, 59, 1-8. [CrossRef]

34. Mohri, K.; Uchiyama, T.; Shen, L.P.; Cai, C.M.; Panina, L.V. Amorphous wire and CMOS IC-based sensitive micro-magnetic sensors (MI sensor and SI sensor) for intelligent measurements and controls. J. Magn. Magn. Mater. 2002, 249, 351-356. [CrossRef]

35. Dufay, B.; Saez, S.; Dolabdjian, C.; Melo, L.G.C.; Yelon, A.; Ménard, D. Development of a high sensitivity Giant MagnetoImpedance magnetometer: Comparison with a commercial Flux-Gate. IEEE Trans. Magn. 2013, 49, 85. [CrossRef]

36. Uchiyama, T.; Mohri, K.; Nakayama, S. Measurement of Spontaneous Oscillatory Magnetic Field of Guinea-Pig Smooth Muscle Preparation Using Pico-Tesla Resolution Amorphous Wire Magneto-Impedance Sensor. IEEE Trans. Magn. 2011, 47, $3070-3073$. [CrossRef]

37. Chen, L.; Bao, C.C.; Yang, H.; Li, D.; Lei, C.; Wang, T.; Hu, H.Y.; He, M.; Zhou, Y.; Cui, D.X. A prototype of giant magnetoimpedance-based biosensing system for targeted detection of gastric cancer cells. Biosens. Bioelectron. 2011, 26, 3246-3253. [CrossRef] [PubMed]

38. Cobeño, A.F.; Zhukov, A.; Blanco, J.M.; Larin, V.; Gonzalez, J. Magnetoelastic sensor based on GMI of amorphous microwire. Sens. Actuat. A Phys. 2001, 91, 95-98. [CrossRef] 
39. Qin, F.X.; Pankratov, N.; Peng, H.X.; Phan, M.H.; Panina, L.V.; Ipatov, M.; Zhukova, V.; Zhukov, A.; Gonzalez, J. Novel magnetic microwires-embedded composites for structural health monitoring applications. J. Appl. Phys. 2010, 107, 09A314. [CrossRef]

40. González-Alonso, D.; González-Legarreta, L.; Corte-León, P.; Zhukova, V.; Ipatov, M.; Blanco, J.M.; Zhukov, A. Magnetoimpedance Response and Field Sensitivity in Stress-Annealed Co-Based Microwires for Sensor Applications. Sensors 2020, 20, 3227. [CrossRef]

41. Vazquez, M.; Chen, D.-X. The magnetization reversal process in amorphous wires. IEEE Trans. Magn. 1995, 31, 1229-1238. [CrossRef]

42. Mohri, K.; Humphrey, F.B.; Kawashima, K.; Kimura, K.; Muzutani, M. Large Barkhausen and Matteucci Effects in FeCoSiB, FeCrSiB, and FeNiSiB Amorphous Wires. IEEE Trans. Magn. 1990, 26, 1789-1791. [CrossRef]

43. Zhukova, V.; Zhukov, A.; Blanco, J.M.; Gonzalez, J.; Ponomarev, B.K. Switching field fluctuations in a glass coated Fe-rich amorphous microwire. J. Magn. Magn. Mat. 2002, 249, 131-135. [CrossRef]

44. Zhukova, V.; Blanco, J.M.; Chizhik, A.; Ipatov, M.; Zhukov, A. AC-current-induced magnetization switching in amorphous microwires. Front. Phys. 2018, 13, 137501. [CrossRef]

45. Zhukova, V.; Corte-Leon, P.; González-Legarreta, L.; Talaat, A.; Blanco, J.M.; Ipatov, M.; Olivera, J.; Zhukov, A. Review of Domain Wall Dynamics Engineering in Magnetic Microwires. Nanomaterials 2020, 10, 2407. [CrossRef] [PubMed]

46. Ogasawara, I.; Ueno, S. Preparation and properties of amorphous wires. IEEE Trans. Magn. 1995, 31, 1219-1223. [CrossRef]

47. Rudkowski, P.; Rudkowska, G.; Strom-Olsen, J.O. The fabrication of fine metallic fibers by continuous melt extraction and their magnetic and mechanical properties. Mater. Sci. Eng. A 1991, 133, 158-161. [CrossRef]

48. Zhukova, V.; Zhukov, A.; Kraposhin, V.; Prokoshin, A.; Gonzalez, J. Magnetic properties and GMI of soft magnetic amorphous fibers. Sens. Actuat. A Phys. 2003, 106, 225-229. [CrossRef]

49. Baranov, S.A.; Larin, V.S.; Torcunov, A.V. Technology, Preparation and Properties of the Cast Glass-Coated Magnetic Microwires. Crystals 2017, 7, 136. [CrossRef]

50. Chiriac, H.; Lupu, N.; Stoian, G.; Ababei, G.; Corodeanu, S.; Óvári, T.-A. Ultrathin nanocrystalline magnetic wires. Crystals 2017, 7, 48. [CrossRef]

51. Corte-Leon, P.; Zhukova, V.; Ipatov, M.; Blanco, J.M.; González, J.; Churyukanova, M.; Taskaev, S.; Zhukov, A. The effect of annealing on magnetic properties of "Thick" microwires. J. Alloys Compd. 2020, 831, 150992. [CrossRef]

52. Taylor, G.F. A Method of Drawing Metallic Filaments and a Discussion of their Properties and Uses. Phys. Rev. 1924, $23,655$. [CrossRef]

53. Ulitovsky, A.V.; Avernin, N.M. Method of Fabrication of Metallic Microwire. USSR Patent 161325, 19.03.64, Bulletin No. 7, 19 March 1964

54. Kraus, L.; Schneider, J.; Wiesner, H. Ferromagnetic resonance in amorphous alloys prepared by rapid quenching from the melt. Czech. J. Phys. B 1976, 26, 601-602. [CrossRef]

55. Zhukov, A.; Zhukova, V.; González, J.; Larin, V.S.; Torcunov, A.V. Glass-Coated Ultrafine Amorphous Wires Having a Giant Magnetoimpedance (GMI) Effect at High Frequencies. European Patent EP2148338A1, 27 January 2010.

56. Zhukov, A.; Ipatov, M.; Talaat, A.; Blanco, J.M.; Hernando, B.; Gonzalez-Legarreta, L.; Suñol, J.J.; Zhukova, V. Correlation of Crystalline Structure with Magnetic and Transport Properties of Glass-Coated Microwires. Crystals 2017, 7, 41. [CrossRef]

57. Badinter, E.Y.A.; Berman, N.R.; Drabenko, I.F.; Zaborovsky, V.I.; Zelikovsky, Z.I.; Cheban, V.G. Cast Microwires and Its Properties; Shtinica: Kishinev, USSR, 1973.

58. Zhukov, A.; Shuvaeva, E.; Kaloshkin, S.; Churyukanova, M.; Kostitcyna, E.; Zhdanova, M.; Talaat, A.; Ipatov, M.; Zhukova, V. Studies of interfacial layer and its effect on magnetic properties of glass-coated microwires. J. Electr. Mater. 2016, 45, $2381-2387$. [CrossRef]

59. Zhukov, A.; Kostitcyna, E.; Shuvaeva, E.; Kaloshkin, S.; Churyukanova, M.; Sudarchikova, V.; Talaat, A.; Zhukova, V. Effect of composite origin on magnetic properties of glass-coated microwires. Intermetallics 2014, 44, 88-93. [CrossRef]

60. Zhukov, A.; Shuvaeva, E.; Kaloshkin, S.; Churyukanova, M.; Kostitcyna, E.; Talaat, A.; Ipatov, M.; Gonzalez, J.; Zhukova, V. Studies of the Defects Influence on Magnetic Properties of Glass-Coated Microwires. IEEE Trans. Magn. 2014, 50, 2006604. [CrossRef]

61. Zhukov, A.; Shuvaeva, E.; Kaloshkin, S.; Churyukanova, M.; Kostitcyna, E.; Sudarchikova, V.; Talaat, A.; Ipatov, M.; Zhukova, V. Influence of the defects on magnetic properties of glass-coated microwires. J. Appl. Phys. 2014, 115, 17A305. [CrossRef]

62. Velázquez, J.; Vázquez, M.; Hernando, A.; Savage, H.T.; Wun-Fogle, M. Magnetoelastic anisotropy in amorphous wires due to quenching. J. Appl. Phys. 1991, 70, 6525-6527. [CrossRef]

63. Antonov, A.S.; Borisov, V.T.; Borisov, O.V.; Prokoshin, A.F.; Usov, N.A. Residual quenching stresses in glass-coated amorphous ferromagnetic microwires. J. Phys. D Appl. Phys. 2000, 33, 1161-1168. [CrossRef]

64. Chiriac, H.; Óvári, T.-A.; Corodeanu, S.; Ababei, G. Interdomain wall in amorphous glass-coated microwires. Phys. Rev. B 2007, 76, 214433. [CrossRef]

65. Zhukova, V.; Blanco, J.M.; Ipatov, M.; Zhukov, A. Magnetoelastic contribution in domain wall dynamics of amorphous microwires. Phys. B 2012, 407, 1450-1454. [CrossRef]

66. Astefanoaei, I.; Radu, D.; Chiriac, H. Internal stress distribution in DC joule-heated amorphous glass-covered microwires. J. Condens. Matter. Phys. 2006, 18, 2689-2716. [CrossRef]

67. Torcunov, A.V.; Baranov, S.A.; Larin, V.S. The internal stresses dependence of the magnetic properties of cast amorphous microwires covered with glass insulation. J. Magn. Magn. Mater. 1999, 196-197, 835-836. [CrossRef] 
68. Gonzalez-Legarreta, L.; Corte-Leon, P.; Zhukova, V.; Ipatov, M.; Blanco, J.M.; Gonzalez, J.; Zhukov, A. Optimization of magnetic properties and GMI effect of Thin Co-rich Microwires for GMI Microsensors. Sensors 2020, 20, 1558. [CrossRef]

69. Zhukov, A.; Talaat, A.; Ipatov, M.; Zhukova, V. Tailoring of High Frequency Giant Magnetoimpedance Effect of amorphous Co-rich microwires. IEEE Magn. Lett. 2015, 6, 2500104. [CrossRef]

70. Zhukov, A.; Ipatov, M.; Corte-Leon, P.; Blanco, J.M.; González-Legarreta, L.; Zhukova, V. Routes for Optimization of Giant Magnetoimpedance Effect in Magnetic Microwires. IEEE Instrum. Meas. Mag. 2020, 23, 56-63. [CrossRef]

71. Zhukova, V.; Blanco, J.M.; Ipatov, M.; Churyukanova, M.; Taskaev, S.; Zhukov, A. Tailoring of magnetoimpedance effect and magnetic softness of Fe-rich glass-coated microwires by stress-annealing. Sci. Rep. 2018, 8, 3202. [CrossRef]

72. Churyukanova, M.; Semenkova, V.; Kaloshkin, S.; Shuvaeva, E.; Gudoshnikov, S.; Zhukova, V.; Shchetinin, I.; Zhukov, A. Magnetostriction investigation of soft magnetic microwires. Phys. Status Solidi A 2016, 213, 363-367. [CrossRef]

73. Usov, N.; Antonov, A.; Dykhne, A.; Lagar'kov, A. Stress dependence of the hysteresis loops of Co-rich amorphous wire. J. Phys. Condens. Matter. 1998, 10, 2453-2463. [CrossRef]

74. Nderu, J.N.; Yamasaki, J.; Humphrey, F. Switching mechanism in Co based amorphous wire. J. Appl. Phys. 1997, 81, 4036-4038. [CrossRef]

75. Zhukova, V.; Corte-Leon, P.; González-Legarreta, L.; Talaat, A.; Blanco, J.M.; Ipatov, M.; Olivera, J.; Zhukov, A. Optimization of Magnetic Properties of Magnetic Microwires by Post-Processing. Processes 2020, 8, 1006. [CrossRef]

76. Corte-Leon, P.; Zhukova, V.; Ipatov, M.; Blanco, J.M.; Gonzalez, J.; Churyukanova, M.; Baraibar, J.M.; Taskaev, S.; Zhukov, A. Stress dependence of the magnetic properties of glass-coated amorphous microwires. J. Alloys Compd. 2019, 789, 201-208. [CrossRef]

77. Zhukova, V.; Corte-Leon, P.; Ipatov, M.; Blanco, J.M.; Gonzalez-Legarreta, L.; Zhukov, A. Development of Magnetic Microwires for Magnetic Sensor Applications. Sensors 2019, 19, 4767. [CrossRef] [PubMed]

78. Zhukova, V.; Blanco, J.M.; Rodionova, V.; Ipatov, M.; Zhukov, A. Domain wall propagation in micrometric wires: Limits of single domain wall regime. J. Appl. Phys. 2012, 111, 07E311. [CrossRef]

79. Chen, D.-X.; Dempsey, N.M.; Vázquez, M.; Hernando, A. Propagating domain wall shape and dynamics in iron-rich amorphous wires. IEEE Trans. Magn. 1995, 31, 781-790. [CrossRef]

80. Richter, K.; Varga, R.; Kováč, J.; Zhukov, A. Controlling the Domain Wall Dynamics by Induced Anisotropies. IEEE Trans. Magn. 2012, 48, 1266-1268. [CrossRef]

81. Zhukov, A.; Blanco, J.M.; Ipatov, M.; Zhukova, V. Fast magnetization switching in thin wires: Magnetoelastic and defects contributions. IEEE Sens. Lett. 2013, 11, 170-176. [CrossRef]

82. Zhukova, V.; Ipatov, M.; Talaat, A.; Blanco, J.M.; Churyukanova, M.; Zhukov, A. Effect of stress annealing on magnetic properties and GMI effect of Co- and Fe-rich microwires. J. Alloys Compd. 2017, 707, 189-194. [CrossRef]

83. Gonzalez-Legarreta, L.; Corte-León, P.; Zhukova, V.; Ipatov, M.; Blanco, J.M.; Churyukanova, M.; Taskaev, S.; Zhukov, A. Route of magnetoimpedance and domain walls dynamics optimization in Co-based microwires. J. Alloys Compd. 2020, 830, 154576. [CrossRef]

84. Zhukov, A.; Gonzalez-Legarreta, L.; Corte-Leon, P.; Ipatov, M.; Blanco, J.M.; Gonzalez, J.; Zhukova, V. Tailoring of Magnetic Softness and Magnetoimpedance of Co-rich Microwires by Stress-annealing. Phys. Stat. Solidi A 2021, 218, 2100130. [CrossRef]

85. González, J.; Vázquez, M.; Barandiarán, J.M.; Madurga, V.; Hernando, A. Different kinds of magnetic anisotropies induced by current annealing in metallic glasses. J. Magn. Magn. Mater. 1987, 68, 151-156. [CrossRef]

86. Luborsky, F.E.; Walter, J.L. Magnetic Anneal Anisotropy in Amorphous Alloys. IEEE Trans. Magn. 1977, 13, 953-956. [CrossRef]

87. Haimovich, J.; Jagielinski, T.; Egami, T. Magnetic and structural effects of anelastic deformation of an amorphous alloy. J. Appl. Phys. 1985, 57, 3581. [CrossRef]

88. Ohnuma, M.; Herzer, G.; Kozikowski, P.; Polak, C.; Budinsky, V.; Koppoju, S. Structural anisotropy of amorphous alloys with creep-induced magnetic anisotropy. Acta Mater. 2012, 60, 1278-1286. [CrossRef]

89. Herzer, G. Amorphous and nanocrystalline soft magnets. In Proceedings of the NATO Advanced Study Institute on Magnetic Hysteresis in Novel Materials, Mykonos, Greece, 1-12 July 1996; Hadjipanayis, G.C., Ed.; Kluwer Academic Publishers: Dordrecht, The Netherlands, 1997; Volume 338, pp. 711-730, NATO ASI Series (Series E: Applied Sciences).

90. Pirota, K.R.; Kraus, L.; Chiriac, H.; Knobel, M. Magnetic properties and GMI in a CoFeSiB glass-covered microwire. J. Magn. Magn. Mater. 2000, 21, L243-L247. [CrossRef]

91. Zhukova, V.; Cobeño, A.F.; Zhukov, A.; Blanco, J.M.; Puerta, S.; Gonzalez, J.; Vázquez, M. Tailoring of magnetic properties of glass coated microwires by current annealing. J. Non-Cryst. Solids 2001, 287, 31-36. [CrossRef]

92. Corte-León, P.; Zhukova, V.; Ipatov, M.; Blanco, J.M.; Gonzalez, J.; Zhukov, A. Engineering of magnetic properties of Co-rich microwires by joule heating. Intermetallics 2019, 105, 92-98. [CrossRef]

93. Corte-León, P.; Zhukova, V.; Ipatov, M.; Blanco, J.M.; Zhukov, A. Effect of Joule heating on giant magnetoimpedance effect and magnetic properties of Co-rich microwires. J. Alloys Compd. 2021, 883, 160778. [CrossRef]

94. Nematov, M.G.; Baraban, I.; Yudanov, N.A.; Rodionova, V.; Qin, F.X.; Peng, H.-X.; Panina, L.V. Evolution of the magnetic anisotropy and magnetostriction in Co-based amorphous alloys microwires due to current annealing and stress-sensory applications. $J$. Alloys Compd. 2020, 837, 155584. [CrossRef]

95. Blanco, J.M.; Zhukov, A.; Gonzalez, J. Torsional Stress Impedance and Magneto-impedance in $\left(\mathrm{Co}_{0.95} \mathrm{Fe}_{0.05}\right)_{72.5} \mathrm{Si}_{12.5} \mathrm{~B}_{15} \mathrm{Amor}_{-}$ phous Wire with Helical Induced Anisotropy. J. Phys. D Appl. Phys. 1999, 37, 3140-3145. [CrossRef] 
96. Popova, A.V.; Odintsov, V.I.; Menshov, S.A.; Kostitsyna, E.V.; Tarasov, V.P.; Zhukova, V.; Zhukov, A.; Gudoshnikov, S.A. Continuous control of a resistance in Co-rich amorphous ferromagnetic microwires during DC Joule heating. Intermetallics 2018, 99, 39-43. [CrossRef]

97. Zhukova, V.; Ipatov, M.; González, J.; Blanco, J.M.; Zhukov, A.P. Development of Thin Microwires with Enhanced Magnetic Softness and GMI. IEEE Trans. Magn. 2008, 44, 3958-3961. [CrossRef]

98. Kohmoto, O.; Ohya, K.; Yamaguchi, N.; Fujishima, H.; Ojima, T. Amorphous FeCoNiSiB alloys having zero magnetostriction. J. Appl. Phys. 1980, 51, 4342. [CrossRef]

99. Schafer, R.; Ho, W.K.; Yamasaki, J.; Hubert, A.; Humphrey, F.B. Anisotropy pinning of domain walls in a soft amorphous magnetic material. IEEE Trans. Magn. 1991, 27, 3678-3689. [CrossRef]

100. Nielsen, O.V.; Nielsen, H.J.V. Stress and field-induced magnetic anisotropy in metallic glasses with positive or negative $\lambda_{\mathrm{s}}$. Solid Stat. Commun. 1980, 35, 281-284. [CrossRef]

101. Barandiarán, J.M.; Hernando, A.; Madurga, V.; Nielsen, O.V.; Vázquez, M.; Vázquez-López, M. Temperature, stress, and structuralrelaxation dependence of the magnetostriction in $\left(\mathrm{Co}_{0.94} \mathrm{Fe}_{0.06}\right)_{75} \mathrm{Si}_{15} \mathrm{~B}_{10}$ glasses. Phys. Rev. B 1987, 35, 5066-5071. [CrossRef] [PubMed]

102. Zhukov, A.; Talaat, A.; Churyukanova, M.; Kaloshkin, S.; Semenkova, V.; Ipatov, M.; Blanco, J.M.; Zhukova, V. Engineering of magnetic properties and GMI effect in Co-rich amorphous microwires. J. Alloys Compd. 2016, 664, 235-241. [CrossRef]

103. Corte-Leon, P.; Zhukova, V.; Blanco, J.M.; González-Legarreta, L.; Ipatov, M.; Zhukov, A.A. Stress-induced Magnetic Anisotropy Enabling Engineering of Magnetic Softness of Fe-rich Amorphous Microwires. J. Magn. Magn. Mater. 2020, 510, 166939. [CrossRef]

104. Zhukov, A.; Churyukanova, M.; Kaloshkin, S.; Semenkova, V.; Gudoshnikov, S.; Ipatov, M.; Talaat, A.; Blanco, J.M.; Zhukova, V. Effect of annealing on magnetic properties and magnetostriction coefficient of Fe-Ni-based amorphous microwires. J. Alloys Compd. 2015, 651, 718-723. [CrossRef]

105. Zhukova, V.; Blanco, J.M.; Corte-Leon, P.; Ipatov, M.; Churyukanova, M.; Taskaev, S.; Zhukov, A. Grading the magnetic anisotropy and engineering the domain wall dynamics in Fe-rich microwires by stress-annealing. Acta Mater. 2018, 155, 279-285. [CrossRef]

106. Usov, N.A.; Antonov, A.S.; Lagar'kov, A.N. Theory of giant magneto-impedance effect in amorphous wires with different types of magnetic anisotropy. J. Magn. Magn. Mater. 1998, 185, 159-173. [CrossRef]

107. Corte-Leon, P.; Zhukova, V.; Blanco, J.M.; Ipatov, M.; Taskaev, S.; Churyukanova, M.; Gonzalez, J.; Zhukov, A. Engineering of magnetic properties and magnetoimpedance effect in Fe-rich microwires by reversible and irreversible stress-annealing anisotropy. J. Alloys Compd. 2021, 855, 157460. [CrossRef]

108. Zhukov, A.; Corte-Leon, P.; Gonzalez-Legarreta, L.; Ipatov, M.; Blanco, J.M.; Gonzalez, A.; Zhukova, V. Advanced functional magnetic microwires for technological applications. J. Phys. D Appl. Phys. submitted.

109. Gonzalez, A.; Zhukova, V.; Ipatov, M.; Corte-Leon, P.; Blanco, J.M.; Zhukov, A. Effect of Joule heating on GMI and magnetic properties of Fe-rich glass-coated microwires. AIP Adv. in press.

110. Zhukov, A.; Zhukova, V.; Larin, V.; Blanco, J.M.; Gonzalez, J. Tailoring of magnetic anisotropy of Fe-rich microwires by stress induced anisotropy. Phys. B 2006, 384, 1-4. [CrossRef]

111. Goto, T. Fe-B and Fe-Si-B system alloy filaments produced by glass-coated melt spinning. Trans. Jpn. Inst. Met. 1980, 21, 219-224. [CrossRef]

112. Corte-León, P.; Zhukova, V.; Blanco, J.M.; Chizhik, A.; Ipatov, M.; Gonzalez, J.; Fert, A.; Zhukov, A. Engineering of domain wall propagation in magnetic microwires with graded magnetic anisotropy. Appl. Mater. Today 2021, 101263. [CrossRef]

113. Skomski, R.; George, T.A.; Sellmyer, D.J. Nucleation, and wall motion in graded media. J. Appl. Phys. 2008, 103, 07F531. [CrossRef]

114. Tsai, J.-L.; Tzeng, H.-T.; Liu, B.-F. Magnetic properties and microstructure of graded Fe/FePt films. J. Appl. Phys. 2010, 107, 113923. [CrossRef]

115. Zha, C.L.; Dumas, R.K.; Fang, Y.Y.; Bonanni, V.; Nogués, J.; Åkerman, J. Continuously graded anisotropy in single $\left(\mathrm{Fe}_{53} \mathrm{Pt}_{47}\right)_{100-\mathrm{x}} \mathrm{Cu}_{\mathrm{x}}$ films. Appl. Phys. Lett. 2010, 97, 182504. [CrossRef]

116. Kronmüller, H. Micromagnetism and microstructure of amorphous alloys. J. Appl. Phys. 1981, 52, 1859-1864. [CrossRef]

117. Kronmüller, H.; Fähnle, M.; Domann, M.; Grimm, H.; Grimm, R.; Groger, B. Magnetic properties of amorphous ferromagnetic alloys. J. Magn. Magn. Mater. 1979, 13, 53-70. [CrossRef]

118. Kronmüller, H.; Groger, B. Domains, domain walls and the coercive field of amorphous ferromagnets. J. Phys. 1981, 42, 1285-1292. [CrossRef]

119. Wang, H.; Qin, F.X.; Xing, D.W.; Cao, F.Y.; Wang, X.D.; Peng, H.X.; Sun, J.F. Relating residual stress and microstructure to mechanical and giant magneto-impedance properties in cold-drawn Co-based amorphous microwires. Acta Mater. 2012, 60, 5425-5436. [CrossRef]

120. Phan, M.H.; Peng, H.X. Giant Magnetoimedance Materials: Fundamentals and Applications. Prog. Mater. Sci. 2008, 53, 323-420. [CrossRef]

121. Ménard, D.; Britel, M.; Ciureanu, P.; Yelon, A. Giant magnetoimpedance in a cylindrical magnetic conductor. J. Appl. Phys. 1998, 84, 2805-2814. [CrossRef]

122. Nakayama, K.S.; Chiba, T.; Tsukimoto, S.; Yokoyama, Y.; Shima, T.; Yabukami, S.H. Ferromagnetic resonance in soft-magnetic metallic glass nanowire and microwire. Appl. Phys. Lett. 2014, 105, 202403. [CrossRef] 